Renata Frazão

\title{
Análise citoarquitetônica e imunoistoquímica de estruturas do sistema visual de macacos-prego (Cebus apella)
}

Tese de Doutorado apresentada ao Instituto de Ciências Biomédicas III, da Universidade de São Paulo, para a obtenção do título de Doutor em Ciências Morfofuncionais.

Orientador: Maria Inês Nogueira. Prof. Associado.

São Paulo

2008 


\section{RESUMO}

Frazão, R. Análise Citoarquitetônica e imunoistoquímica de estruturas do sistema visual de macacos- prego (Cebus apella). [Tese de Doutorado]. São Paulo: Instituto de Ciências Biomédicas da Universidade de São Paulo, 2008.

O estudo do sistema visual de macacos-prego, através da caracterização química da retina, e demonstração de suas vias eferentes pela injeção do traçador toxina colérica subunidade B (CTb) representa importante questão devido as possiveís diferenças interespecíficas deste sistema principalmente quanto ao aspecto evolutivo. Foram utilizados cinco macacos-prego adultos, com peso médio de 2 kg, provenientes do Núcleo de Procriação de Macacos-prego da Faculdade de Odontolgia do Campus de Araçatuba - UNESP. Foi efetuada a injeção intraocular de $100 \mu \mathrm{l}$ de solução aquosa de CTb a 1\%, contendo $10 \%$ de dimetil-sulfóxido. A perfusão dos animais foi realizada 15 dias após a injeção. Os olhos foram removidos, sendo o olho contralateral utilizado para análise da retina. Os encéfalos foram seccionados em secções frontais submetidas à imunoistoquímica com o uso do anticorpo contra a CTb para identificação das projeções retinianas. A caracterização imunoistoquímica da retina foi realizada com uso de diversos marcadores, dentre estes o resultado mais signficativo foi o reconhecimento nesta espécie de dois tipos distintos de células bipolares, além disto, subunidades de receptores gabaérgicos podem co-localizar em retinas de macacos-prego, diferente dos resultados apresentados em todas as espécies de mamíferos já analisadas. As projeções da retina foram observadas em todas as estruturas do sistema visual primário, óptico acessório além de projeções para áreas adicionais, não relacionadas a formação da imagem como o sistema de temporização circadiana. Os resultados evidenciam diferenças interespecíficas sugerindo cautela na extrapolação dos resultados adquiridos em diferentes espécies.

Palavras-chave: Sistema visual, macacos-prego, toxina colérica subunidade B, sistema de temporização circadiana, projeção retiniana. 


\begin{abstract}
Frazão, R. Cytoarchitectural and immunohistochemical analysis of the visual system of tufted capuchin (Cebus apella). [Ph.D. thesis]. São Paulo: Biomedical Sciences Institute of University of São Paulo, 2008.

The present study aims to characterize cytochemically the retina of the tufted capuchin monkey, as well as analyze the pattern of retinal projections to structures of the CNS. Were used five tufted capuchin monkeys (average weight of $2 \mathrm{~kg}$ ) from the Center of Tufted Capuchin Reproduction of UNESP's School of Odontology, Araçatuba Campus. The monkeys received a single intraocular injection (in the volume of $100 \mu$ ) of the neuronal tracer cholera toxin subunit B CTb (1:100, diluted in distilled water containing 10\% dimethylsulfoxide). The animals were perfused 15 days after the injection. The retina from the contralateral eyeball was removed to immunohistochemical analysis. The brain was removed from the skull, sectioned into frontal sections and processed with immunohistochemical techniques against CTb to identify the projections from the retina to the CNS. Several cell markers were used to characterize cytochemically different cell types in the retina. The most striking result was the identification of two unique types of bipolar cells. In addition, the tufted capuchin retina, unlike other mammals species analyzed in the literature, shows co-localization with gabaergic receptors. As expected, projections from the retina were observed in all structures of the primary visual system and optic accessory. As a complementary data, retinal projections were also observed in areas not related to the image processing, such as the circadian control system. Overall our results showed several interspecies differences and suggests that comparison of the visual system between species must be undertaken with great caution.
\end{abstract}

Keywords: Visual system, tufted capuchin, cholera toxin subunit B, circadian system, retinal projections. 


\section{INTRODUÇÃO}

\subsection{Retina}

A retina é uma fina lâmina de tecido nervoso (cerca de $200 \mu \mathrm{m}$ de espessura) que se deslocou do encéfalo para o fundo do olho durante o desenvolvimento. Sua função é converter a informação óptica em imagem neural que será transmitida via nervo óptico à diversos núcleos para análise e composição da imagem. Assim, sua função é associar aspectos temporais, espaciais e cromáticos da informação visual, sendo os sinais resultantes transmitidos para áreas visuais centrais (Kalloniatis, Fletcher, 2004; Sterling, Demb, 2004).

A retina apresenta três camadas celulares bem organizadas, cada qual representada por tipos celulares específicos, que se distinguem por suas características morfológicas, conectivas, neuroquímicas, e funcionais (Rodieck, Brening, 1983; Sterling, 1983).

Em adição aos fotorreceptores, sensíveis à luz, há ainda cinco classes celulares de neurônios e um tipo principal de célula da glia, as células de Müller. A camada nuclear externa (ONL) contém os corpos celulares de fotorreceptores (cones e bastonetes) e processos das células de Müller. As células de Müller se estendem por todas as camadas da retina e são responsáveis pela formação da membrana limitante externa, em conjunto com os segmentos externos dos fotorreceptores, e da membrana limitante interna, que forma uma barreira entre a retina e o humor vítreo (Dowling, 2002).

\subsubsection{Fotorreceptores}

Os fotorreceptores, cones e bastonetes, são células alongadas que apresentam os segmentos externos direcionados para a região posterior do globo ocular, onde estão envolvidos por epitélio pigmentar. O segmento externo de cada fotorreceptor contém cerca de 900 discos membranosos, posicionados perpendicularmente em relação ao longo eixo da célula. A superfície do disco é preenchida por cerca de 60.000 moléculas do fotopigmento rodopsina (Pugh, Lamb, 1993). Os axônios dos fotorreceptores normalmente são curtos, cerca de $50 \mu \mathrm{m}$ ou menos, com exceção daqueles na fóvea que podem ter $500 \mu \mathrm{m}$ de comprimento. Ambos terminam, sem se ramificar na camada plexiforme externa (OPL), em sinapse única altamente especializada (Polyak, 1941; Schein, 1988; Hsu et al., 1998). Em retinas de 
macacos-prego estima-se que existam aproximadamente 48 milhões de bastonetes e 3.8 milhões de cones (Andrade da Costa, Hokoc, 2000).

Em condição de baixa intensidade de luz apenas bastonetes tem sensibilidade suficiente para capturar os poucos fótons de luz disponíveis. A visão colorida não é possível esta condição, pois os sinais de um simples detector, os bastonetes, não são capazes de diferenciar entre modulações espectrais. Já em condição de alta intensidade de luz, muitos cones (cerca de 90\%) estão relacionados à comprimentos de ondas intermediários, com pico de sensibilidade de 550nm, denominados de $M$ ou verde e, poucos estão relacionados à comprimentos de ondas curtos, denominados de S ou azul (Jacobs, 1993; Nathans, 1999).

Primatas do Velho Mundo (incluindo humanos) e alguns primatas do Novo Mundo, tradicionalmente divididos em duas famílias principais: Callithricidae, que incluem: macaco coruja, macaco esquilo, sagüis e micos e, Cebidae, que incluem várias subfamílias como cebus, macaco parauacu e macaco aranha, são especiais por serem tricromáticos, o que significa que estes apresentam um tipo adicional de cone relacionado à comprimentos de ondas longos, com pico de sensibilidade de aproximadamente $570 \mathrm{~nm}$ (denominados de $\mathrm{L}$ ou vermelho) (Neitz, Neitz e Jacobs, 1991).

Os cones respondem aos estímulos luminosos com hiperpolarização graduada e liberam o glutamato no seu terminal sináptico especializado denominado de pedículo (Figura 1b). A liberação do glutamato é alta em condições de escuro é reduzida pela luminosidade (Haverkamp, Grunert e Wassle, 2000).

Os pedículos contêm três tipos de especializações sinápticas: pedículos de cones L e M realizam contatos com seu vizinho imediato e com as esférulas dos bastonetes (o terminal sináptico dos bastonetes) através de sinapses elétricas (gap junctions), nas quais a conexina 36 é expressa (Cohen, 1965; Baylor, Fuortes e O'Bryan, 1971; Raviola, Gilula, 1973; Tsukamoto et al., 1992; Feigenspan et al., 2004; Hornstein, Verweij e Schnapf, 2004; Li, DeVries, 2004); realizam sinapses do tipo flat com as células bipolares OFF em sua base (Dowling, Boycott, 1966); e os pedículos apresentam ainda invaginações, cada qual contendo normalmente uma sinapse em fita, pré sináptica, e três ou quatro processos que a ocupam, dois elementos laterais, dendritos de células horizontais, um de uma célula com campo de ação amplo e outro de uma célula com campo de ação restrito (Stell, 1965), e um ou dois dendritos de células bipolares do tipo ON. Os processos das células horizontais penetram profundamente na 
invaginação terminando perto do terminal sináptico, enquanto que, os processos das células bipolares ficam mais distantes (Figura 1b) (Dowling, Boycott, 1966; Chun et al., 1996).

Muitos dendritos de células bipolares ON também realizam sinapses do tipo flat, evidenciando que a chave da diferença funcional entre dendritos de células ON e OFF não depende da morfologia da sinapse envolvida, mas sim do tipo de receptor glutamatérgico expresso pelos respectivos dendritos. As células bipolares OFF expressam receptores glutamatérgicos ionotrópicos, AMPA (do inglês alpha-amino-3-hydroxy-5-methyl-4isoxazolepropionic acid) e kainato, assim como os dendritos de células horizontais, enquanto que, as células bipolares ON expressam o receptor glutamatérgico metabotrópico do tipo seis (mGluR6) (Masu et al., 1995; DeVries, Schwartz, 1999; Vardi et al., 2000; Haverkamp, Grunert e Wassle, 2001b). As células horizontais e as células bipolares OFF associadas à cones são hiperpolarizadas pela luz, e as células bipolares ON associadas à cones são despolarizadas (Wassle, 2004).

As esférulas dos bastonetes contêm apenas uma zona ativa com uma sinapse em fita e uma invaginacão. A invaginacão apresenta dois tipos de processos pós sinápticos: dendritos de células horizontais e dendritos de células bipolares. As espículas dendríticas das células horizontais penetram profundamente na invaginacão dos bastonetes para aproximar seus receptores glutamatérgicos do local de liberação das vesículas sinápticas. Os dendritos de duas ou mais células bipolares penetram na invaginacão, mas estão localizados longe do local de liberação das vesículas sinápticas (Figura 1c) (Rao-Mirotznik et al., 1995).

Dos terminais sinápticos de cones e bastonetes, os sinais são transferidos para as células bipolares e células horizontais. As células horizontais providenciam interações laterais na OPL. Um tipo de célula bipolar associada à bastonetes e pelo menos nove tipos de células bipolares associadas à cones, transferem os sinais luminosos para a camada plexiforme interna (IPL), na qual estes sinais podem interagir com dendritos de células amácrinas e células ganglionares.

\subsubsection{Células horizontais}

Os corpos das células horizontais estão localizados na porção superior da camada nuclear interna (INL), e seus processos realizam sinapses exclusivamente na OPL (Figura 1a). 
As células horizontais se comunicam uma com as outras eletricamente. A força desta comunicação varia em estados adaptativos e é modulada pela dopamina secretada por células amácrinas (Weiler et al., 2000).

Estudos com diversas espécies de animais concluem que a maioria dos mamíferos placentários contêm dois tipos de células horizontais, com morfologia distinta, denominadas como células de tipo A e tipo B (Boycott, 1988) com exceção de ratos, camundongos e gerbils que apresentam somente células do tipo B (Peichl, Gonzalez-Soriano, 1994).

As células do tipo B apresentam dendritos que contactam cones e axônios que contactam bastonetes, enquanto que, as células do tipo A não apresentam axônios, porém apresentam maior arborização dendrítica e contactam apenas cones. Ambas as células não são seletivas para os tipos espectrais dos cones (Boycott, 1988).

Em primatas os dois tipos de células horizontais denominadas de células horizontais HI (HI) e células horizontais HII (HII), apresentam axônios. As células HI, correspondem ao tipo B, têm corpos grandes, dendritos radiados, e um longo axônio que termina arborizando e se conectando com as esférulas dos bastonetes (Boycott, Kolb, 1973; Kolb, Mariani e Gallego, 1980; Mariani, 1984b; Boycott, Hopkins e Sperling, 1987; Boycott, 1988; Dacheux, Raviola, 1990). Em contrapartida, as células HII, correspondentes ao tipo A, têm corpos pequenos, dendritos ondulados, e axônios que contactam apenas cones (Kolb, Mariani e Gallego, 1980; Mariani, 1984b; Boycott, Hopkins e Sperling, 1987). Existem evidências de que as células HII realizam sinapses com todos os cones L, M e S, com importância maior no contato com os cones $\mathrm{S}$, enquanto que, as células $\mathrm{HI}$ contactam cones $\mathrm{L}$ e $\mathrm{M}$, realizando conexões esparsas ou não realizando conexões com os cones S (Ahnelt, Kolb, 1994a; Dacey et al., 1996; Chan, Grunert, 1998).

Um terceiro tipo de célula horizontal, célula HIII, foi demonstrada em retinas de diversos mamíferos, inclusive humanos. As células HIII são morfologicamente semelhantes às células HI, seus dendritos são grandes e assimétricos, e algumas têm processos que terminam na camada mais externa da IPL (Famiglietti, 1990; Kolb, Linberg e Fisher, 1992; Ahnelt, Kolb, 1994a; b; Kolb et al., 1994). Entretanto, outros pesquisadores classificaram células com as mesmas características morfológicas em retinas de primatas como sendo células HI (Boycott, Kolb, 1973; Boycott, Hopkins e Sperling, 1987; Boycott, 1988; Wassle, Boycott e Rohrenbeck, 1989; Dacey et al., 1996; Chan, Goodchild e Martin, 1997). 
Tradicionalmente assume-se que as células horizontais liberam o neurotransmissor inibitório ácido gama aminobutírico (GABA) e provocam retroalimentação negativa nos terminais sinápticos dos fotorreceptores. Duas hipóteses propõem funções para as células horizontais, uma delas assume que estas células expressam conexina em seus prolongamentos, que estão inseridos nos pedículos e nas esférulas. As correntes que fluem através de canais formados por conexinas mudam o potencial extracelular nas invaginações e altera as curvas de ativação nos canais de $\mathrm{Ca}^{2+}$. Através deste mecanismo elétrico de retroalimentação, as células horizontais poderiam modular a liberação de glutamato dos cones e dos bastonetes (Kamermans et al., 2001). A segunda hipótese também postula a modulação de canais de $\mathrm{Ca}^{2+}$ que regulam a liberação de glutamato de cones, entretanto, o mecanismo responsável seria a mudança do $\mathrm{pH}$ na invaginação, provocado por um íon transportador voltagem dependente através da membrana das células horizontais (Hirasawa, Kaneko, 2003). Existem ainda evidências de que a liberação de GABA pelas células horizontais, dependente de luz, seja capaz de inibir dendritos de células bipolares (Hombach et al., 2004).

\subsubsection{Células bipolares}

Atualmente são conhecidos em retinas de primatas onze tipos de células bipolares associadas à cones, e um tipo de célula bipolar associada à bastonetes (Figura 2) (Mariani, 1984b; Boycott, Wassle, 1991; Kolb, Linberg e Fisher, 1992; Wassle, 2004).

Os axônios das células bipolares ON e OFF terminam em diferentes níveis na IPL, que pode ser dividida em 5 substratos, sendo que, os terminais das células bipolares OFF terminam na porção externa da IPL denominada OFF, e os terminais das células bipolares ON terminam na porção interna da IPL denominada ON (Figura 2) (Cohen, Sterling, 1990b; Boycott, Wassle, 1991; Euler, Schneider e Wassle, 1996; Wassle, 2004).

Uma célula bipolar OFF pode conter receptores ionotrópicos AMPA, resultando em transferência sináptica fásica e, portanto, respostas transientes à luz. Outros tipos de células bipolares OFF podem conter receptores kainato, resultando em transferência sináptica tônica e resposta sustentada à luz (DeVries, 2000). Os axônios destas células bipolares que transportam impulsos fásicos terminam na porção média da IPL, enquanto aqueles que transportam impulsos tônicos à luz terminam na porção externa da IPL (Awatramani, 
Slaughter, 2000; Wu, Gao e Maple, 2000). O mesmo parece ocorrer em relaçãos aos impulsos transportados pelas células bipolares $\mathrm{ON}$, sendo respostas transientes transferidas para a porção média da IPL, no substrato ON, e respostas tônicas transferidas para a porção interna da IPL (Pan, Hu, 2000). 


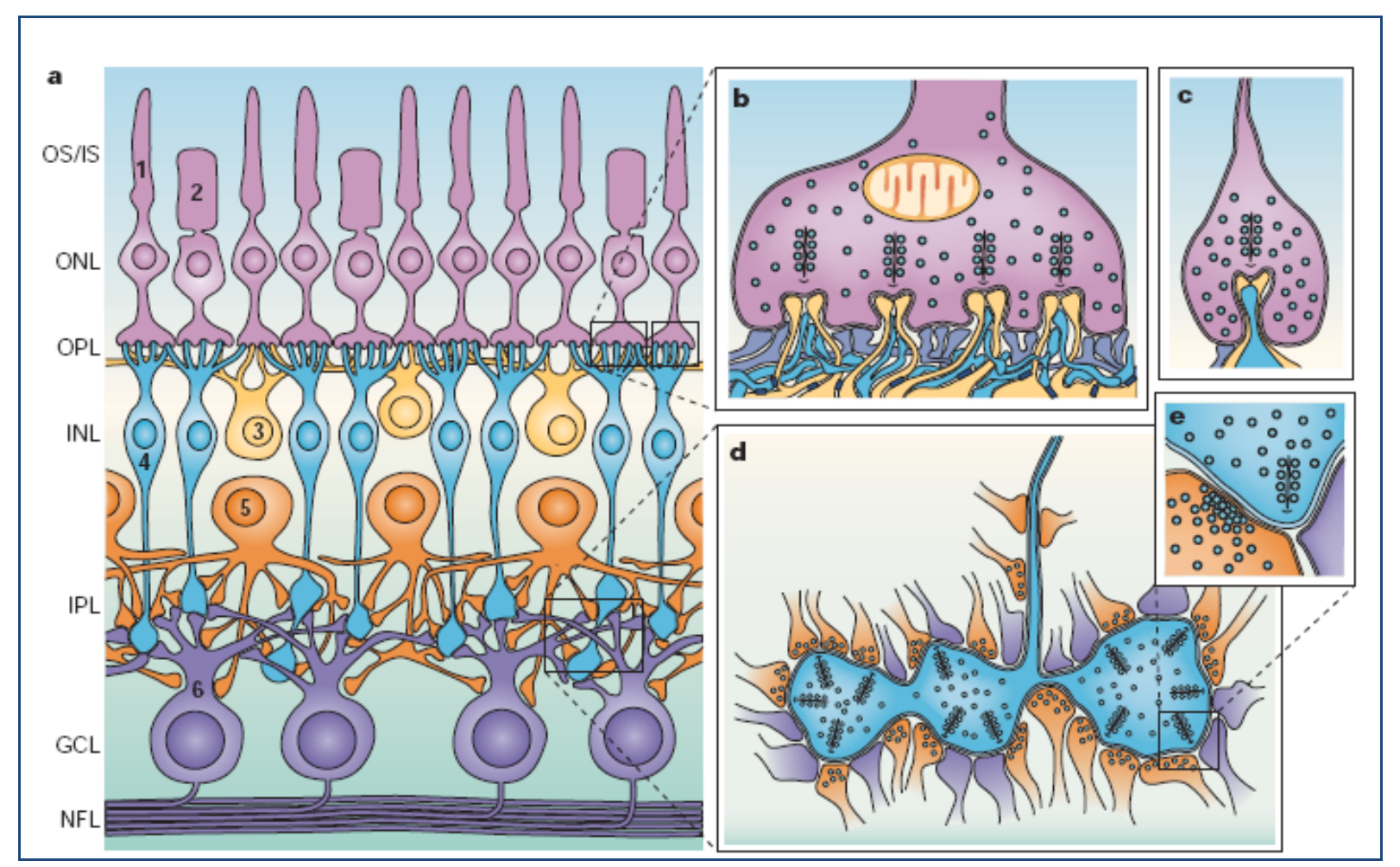

Figura 1. Representação esquemática da retina de mamíferos.

Existem seis tipos de neurônios distribuídos em camadas na retina de mamíferos: Bastonetes (1), cones (2), células horizontais (3), células bipolares (4), células amácrinas (5) e células ganglionares (6). Em "b”, visualiza-se esquema representando os pedículos, o terminal sináptico dos cones, nos quais as sinapses em fitas estão em contraposição aos dendritos de células horizontais (laranja) e aos dendritos de células bipolares ON (azul), este arranjo sináptico é denominado de tríade. Os dendritos das células bipolares OFF realizam sinapses com a base dos pedículos (roxo). Em "c" representação esquemática de uma esférula, o terminal sináptico dos bastonetes, na qual a sinapse em fita está em contraposição aos dendritos de células horizontais (laranja) e ao dendrito de uma célula bipolar (azul). O dendrito de uma célula bipolar OFF realiza sinapse com a base da esférula (roxo). Em “d” visualizase o terminal sináptico de uma célula bipolar associada à cones (azul) que contém cerca de 50 sinapses em fita e realiza sinapses com processos de células amácrinas pós sinápticas (laranja) e dendritos de células ganglionares (roxo). Em “e” uma aproximação da sinapse entre a célula bipolar (azul), processo da célula amácrina (laranja) e dendrito da célula ganglionar (roxo). As células amácrinas realizam sinapses em retroalimentação com as células bipolares. Este arranjo sináptico é denominado de díade. As células amácrinas também realizam numerosas sinapses convencionais com outras células amácrinas e células ganglionares na camada plexiforme interna (IPL). Os processos de algumas células amácrinas também alcançam a camada plexiforme externa (OPL) na qual podem realizar sinapses. (OS IS: segmentos externos e internos de cones e bastonetes; ONL: camada nuclear externa; OPL: camada plexiforme externa; INL: camada nuclear interna; IPL: camada plexiforme interna; GCL: camada de células ganglionares; NFL: camada de fibras do nervo óptico) (Wassle, 2004). 
Além da divisão em ON e OFF, os tipos celulares também podem ser classificados como células bipolares difusas (DB), que realizam sinapses com vários cones (entre 5 e 10), contêm ampla árvore dendrítica e axonal e representam a maioria das células bipolares. As células DB1, DB2 e DB3 são células bipolares OFF, enquanto que as células DB4, DB5 e DB6 são células bipolares ON (Figura 2) (Cohen, Sterling, 1990a; b; Boycott, Hopkins, 1991; Boycott, Wassle, 1991; Calkins et al., 1994; Calkins, Sterling, 1996).

Na retina de primatas além das células classificadas como difusas, foram descritas também células bipolares que realizam sinapses apenas com um pedículo, e células bipolares que realizam sinapses exclusivamente com pedículos de cones S. A árvore dendrítica das células bipolares associadas à cones $\mathrm{S}$ contorna os pedículos dos cones $\mathrm{M}$ e $\mathrm{L}$ para realizar sinapse exclusivamente com cones do tipo S, sendo que, seus axônios realizam sinapses na porção mais interna da IPL, portanto, estas células são caracterizadas como células bipolares ON (Figura 2) (Mariani, 1984a; Kouyama, Marshak, 1992).

Poliack (1941) foi o primeiro a descrever células bipolares conhecidas do inglês como “midget” em retinas de primatas do Novo Mundo. As células midget contêm árvore dendritíca e axonal pequena, que na retina central contacta apenas um único cone e uma única célula ganglionar "midget”. As células midget podem ser subdivididas em dois grupos: células conhecidas do inglês como flat midget bipolar cells (FMB) (células anãs não invaginadas) ou células conhecidas do inglês como invaginating midget bipolar cells (IMB) (células anãs invaginadas) (Figura 2). Os dendritos das células FMB realizam sinapses na base dos pedículos, enquanto que, os dendritos das células IMB podem invaginar nos pedículos de um cone (Boycott, Hopkins, 1991; Calkins et al., 1994).

Na retina central as células midget transportam sinais cromáticos de cones $\mathrm{M}$ e $\mathrm{L}$, na retina periférica as células midget realizam sinapses com mais de cinco cones e provavelmente agrupam os diversos sinais (Wassle et al., 1994). Existem sugestões de que as células midget estejam envolvidas no aumento da resolução espacial e não especificamente no processamento de sinais de cor (Wassle, Boycott, 1991), esta idéia é suportada pela demonstração de que uma célula midget pode realizar sinapse com apenas um cone na retina de primatas monocromáticos, dicromáticos e tricromáticos (Silveira et al., 1998; Chan et al., 2001). 
Apenas em retinas de roedores há descrição de que uma mesma célula bipolar pode receber impulsos diretamente de ambos os tipos de fotorreceptores (Soucy et al., 1998; Hack, Peichl e Brandstatter, 1999; Tsukamoto et al., 2001).

Os axônios das células bipolares associadas à cones se direcionam para a IPL, onde cada tipo seleciona uma camada particular, na qual realizam sinapses com células amácrinas e células ganglionares. Os terminais das células bipolares não apresentam invaginações, portanto não podem realizar contatos com muitos processos pós sinápticos; assim dois processos pós sinápticos alinham-se em ambos os lados da zona ativa nos terminais das células bipolares, formando uma díade (Figura 1d, e) (Dowling, Boycott, 1966). As células bipolares associadas à cones podem ainda realizar sinapses elétricas com outras células bipolares (Cohen, Sterling, 1990b) ou com células amácrinas AII (Kolb, Famiglietti, 1974; Sterling, Freed e Smith, 1988; Strettoi, Dacheux e Raviola, 1990).

Como todos os tipos de células bipolares associadas à cones (exceto aquelas associadas a cones do tipo S) recebem informações dos mesmos cones, seus impulsos espectrais e espaciais são idênticos, uma hipótese sugere que ambos os tipos de células bipolares transmitam diferentes componentes temporais dos sinais provenientes dos cones. $\mathrm{Na}$ verdade, dois tipos de células bipolares diferem temporalmente, uma despolarizando sustentadamente para manter a iluminação, e outras despolarizando transitoriamente (Saito et al., 1985; Dacey et al., 2000; Euler, Masland, 2000).

Os axônios das células bipolares associadas à bastonetes se direcionam, sem se ramificar, para a camada mais profunda da IPL onde não realizam sinapse com células ganglionares, mas sim com um terceiro tipo de neurônio denominado de célula amácrina II (AII) (Figura 3, via ON1) (Kolb, Famiglietti, 1974; Famiglietti, Kolb, 1975; McGuire, Stevens e Sterling, 1984; Raviola, Dacheux, 1987; Strettoi, Dacheux e Raviola, 1990; Wassle et al., 1991). As díades das células bipolares associadas à bastonetes, incluem, portanto um processo de uma célula AII e outro de um outro tipo de célula amácrina. A célula AII nunca realiza sinapse recíproca na díade com a célula bipolar, mas os outros tipos de células amácrinas podem realizar. Entretanto, dendritos das células ganglionares do tipo $\alpha$ também podem ser encontrados nas díades de células bipolares associadas à bastonetes (McGuire, Stevens e Sterling, 1984; Freed, Smith e Sterling, 1987; Freed, Sterling, 1988). 


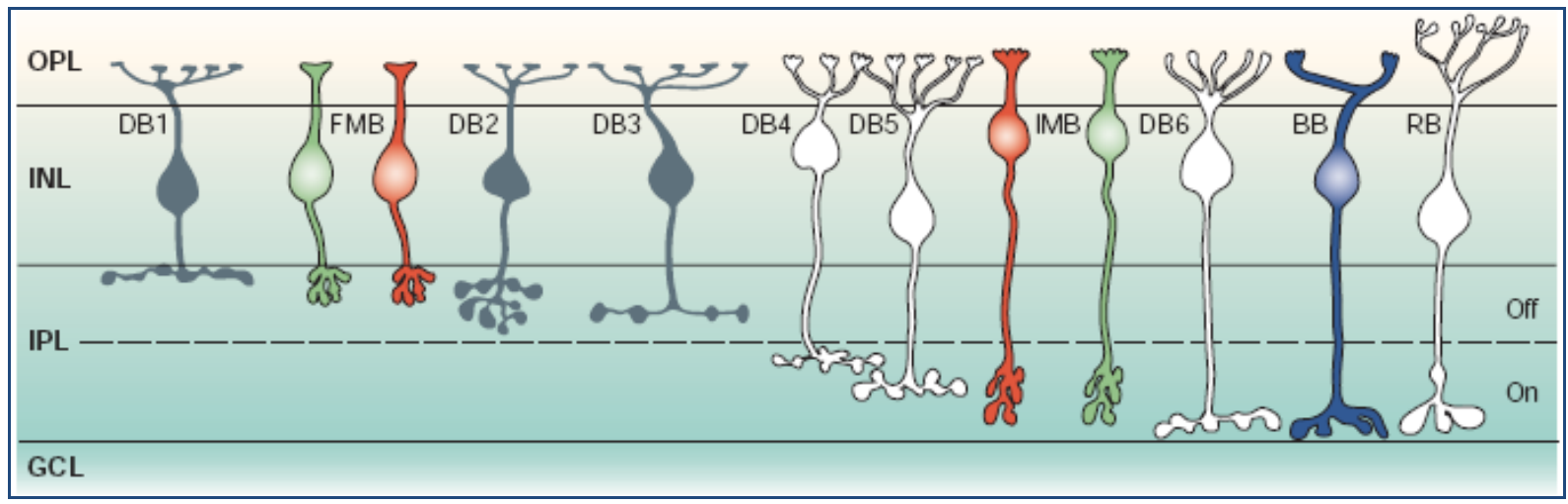

Figura 2. Células bipolares em retinas de primatas.

As células foram analisadas pelo método de Golgi e são demonstradas aqui esquematicamente em secção vertical. Os axônios terminam em diferentes níveis na camada plexiforme interna (IPL); aqueles axônios que se ramificam na porção mais externa da IPL são os de células bipolares OFF associadas à cones; aqueles axônios que se ramificam na porção mais interna da IPL são de células bipolares ON. As células bipolares difusas (DB1-DB6) realizam sinapses de forma não seletiva com cerca de 5 a 10 pedículos de cones L e cones M. Algumas células difusas também realizam sinapses com o pedículo de cones $\mathrm{S}$. As células bipolares midget (FMB) realizam sinapses com apenas um cone L ou M e transportam um sinal cromático OFF. Um tipo de célula FMB realiza sinapse com o cone $\mathrm{S}$, mas não se sabe se está contribui com vias cromáticas. As células bipolares invaginating midget (IMB) realizam sinapses com apenas um cone L ou M e transpotam sinais cromáticos ON. As células bipolares associadas à cones $\mathrm{S}$ realizam sinapses seletivamente com cerca de 1 a 5 pedículos de cones $\mathrm{S}$ e transportam sinais $\mathrm{ON}$. As células bipolares associadas à bastonetes realizam sinapses com cerca de 6 esférulas de bastonetes na fóvea e cerca de 40 sinapses na periferia e transportam sinais ON (Wassle, 2004). 


\subsubsection{Células amácrinas}

As células AII foram descritas pela primeira vez por Kolb e Famiglietti (1974). Estes autores relataram ainda um outro tipo de célula amácrina pós sinápticas nas díades das células bipolares associadas à bastonetes denominada de célula amácrina I (AI) (Famiglietti, Kolb, 1975). As células AI são células gabaérgicas que possuem amplo campo de ação e realizam sinapses recíprocas com os terminais das células bipolares associadas à bastonetes, modulando, provavelmente, o sinal de transferência do impulso (Wassle et al., 1995).

As células AII são consideradas células glicinérgicas, pois acumulam glicina e são imunorreativas ao anticorpo que caracteriza esta substância, além de possuírem receptores glicinérgicos pré sinápticos (Pourcho, Goebel, 1985; 1987; Sassoe-Pognetto, Wassle e Grunert, 1994). São células pequenas, ramificadas com muitas varicosidades denominadas de apêndices. Em retinas de gatos, coelhos e ratos, estas células representam 10\% da população de células amácrinas, sendo, provavelmente, o tipo celular mais comum nestas espécies (Vaney, 1985; Vaney, Gynther e Young, 1991; Wassle, Grunert e Rohrenbeck, 1993).

As células AII também realizam sinapses elétricas com terminais de células bipolares ON associadas à cones (Figura 3, via ON1) e sinapses químicas inibitórias com células bipolares OFF associadas à cones, sendo que, as células bipolares transmitem os impulsos para as células ganglionares. Esta é a via clássica pela qual transita a informação a partir dos bastonetes em retina de mamíferos (DeVries, Baylor, 1995). O desvio através das células AII para as células bipolares provavelmente permite que a via dos bastonetes ganhe vantagens em relação a circuitaria que envolve as células bipolares associadas à cones. Estudos recentes demonstraram que o sinal dos bastonetes também podem ser transmitidos por vias alternativas. Umas das vias seria por sinapses elétricas entre as esférulas dos bastonetes e os pedículos dos cones (Figura 3, vias ON2 e OFF2) (DeVries, Baylor, 1995), além disto, células bipolares OFF associadas à cones podem contactar diretamente as esférulas dos bastonetes (Figura 3, via OFF3) (Soucy et al., 1998; Hack, Peichl e Brandstatter, 1999; Tsukamoto et al., 2001). Portanto, existem pelo menos 3 circuitos pelos quais transitam os sinais provenientes dos bastonetes, sendo que, como demonstrado em retinas de camundongos, diferentes células ganglionares estão associadas preferencialmente com cada um destes circuitos (Deans et al., 2002). 


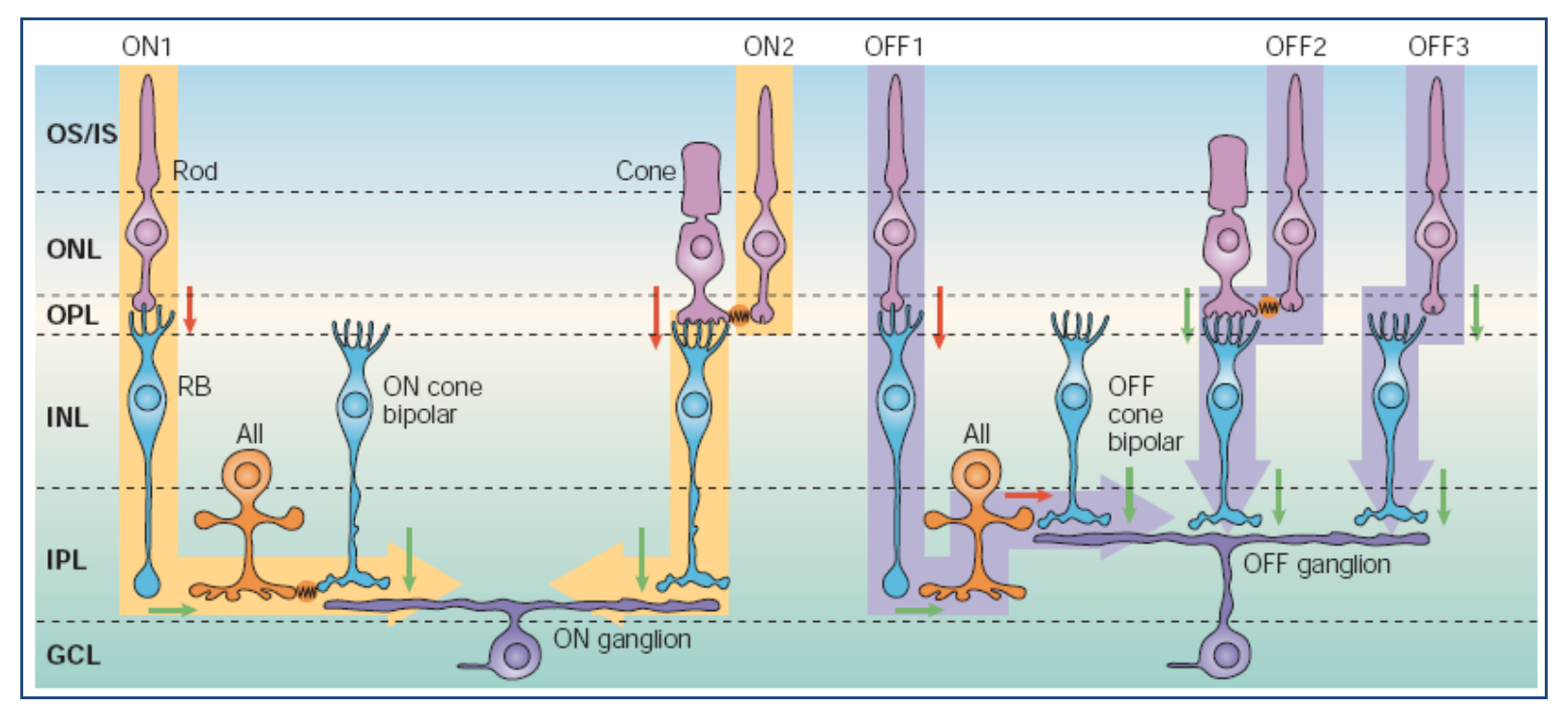

Figura 3. Vias de transmissão na retina de mamíferos.

Na via esquematizada como ON1 os bastonetes (Rod) são hiperpolarizados pela luz e transferem seus sinais para os dendritos de células bipolares associadas à bastonetes (RB) presentes na invaginação das esférulas. Os dendritos das RB contêm o subunidade 6 do receptor ionotrópico para glutamato (mGluR6), causando uma inversão do sinal na sinapse (seta vermelha), sendo, portanto, despolarizadas pela luz (Raviola, Dacheux, 1987). As células RB realizam sinapses com células amácrinas do tipo II (AII) (seta verde) que apresentam receptores glutamatérgicos (AMPA) em seus dendritos. As células AII realizam sinapses elétricas com axônios de células bipolares ON, que por sua vez realizam sinapses com células ganglionares ON (seta verde). Na via esquematizada como OFF1, a via é idêntica à via ON1, mas os impulsos a partir das células AII diferem. Estas células realizam sinapses com os axônios das células bipolares OFF associadas à cones (seta vermelha), que por sua vez realizam sinapses com as células ganglionares OFF (seta verde). Na via descrita como ON2 os impulsos são transmitidos dos bastonetes para os pedículos (por meio de conexina 36 em junções elétricas) e destes os impulsos seguem a via ON até as células ganlionares ON. A via denominada OFF2 é comparável com a via ON2, entretanto, os impulsos são direcionados à células ganglionares OFF. Na via OFF3, as células bipolares OFF associadas à cones realizam sinapses diretamente com a base das esférulas dos bastonetes e transferem os impulsos para células ganglionares OFF (Deans et al., 2002; Demb, Pugh, 2002; Wassle, 2004). OS IS: segmentos externos e internos de cones e bastonetes; ONL: camada nuclear externa; OPL: camada plexiforme externa; INL: camada nuclear interna; IPL: camada plexiforme interna; GCL: camada de células ganglionares; NFL: camada de fibras do nervo óptico). 
As células amácrinas variam em termos de extensão e distribuição de seus processos, e é possível encontrar diferentes referências em relação ao número de subtipos de células amácrinas nas diversas espécies já estudadas (entre 30 e 40). De forma geral estas células podem ser divididas em dois grandes grupos: células amácrinas difusas e células amácrinas estratificadas. As células difusas extendem seus processos por todos os substratos da IPL, enquanto que, as células estratificadas extendem seus processos de forma mais restrita na IPL. Esta simples classificação pode ser expandida para incluir células amácrinas difusas e estratificadas com campo de ação restrito ou com campo de ação amplo, dependendo do quão longe seus processos possam se extender, estando confinados a um, dois, ou vários substratos na IPL (Dowling, 2002).

Algumas células amácrinas com campo de ação restrito recebem impulsos somente de terminais de células bipolares associadas à cones. Estas células realizam retroalimentação recíproca entre os terminais das células bipolares e ganglionares e também podem ser células ON ou OFF (Polyak, 1941; Kolb, Nelson e Mariani, 1981).

Células amácrinas denominadas de "starbust” (estreladas) foram descritas em diversas espécies, inclusive primatas. Estas células podem se associar com outras de seu próprio tipo e realizar sinapses com células ganglionares que apresentam direção seletiva. Em primatas as células "starbust" realizam sinapses com as células ganglionares denominadas "parasol" (Tauchi, Masland, 1984; Rodieck, 1989; Vaney, Whitington e Young, 1989; Jacoby et al., 1996). Existem diferentes populações de células "starbust” para os níveis ON e OFF da IPL, estas células respondem fasicamente ao impulso glutamatérgico bipolar, pois possuem receptores do tipo kainato (Linn et al., 1991) e liberam impulsos de acetilcolina para as células ganglionares (Masland, Mills e Hayden, 1984; Massey, Redburn, 1985). A acetilcolina se une à receptores nicotínicos e excita as células ganglionares (Schmidt, Humphrey e Wassle, 1987; Kaneda, Hashimoto e Kaneko, 1995). Alguns estudos sugerem que estas células disparam potenciais de ação (Bloomfield, 1992; Jensen, 1995; Cohen, 2001), enquanto outros relatam que estas apenas respondem passivamente ao impulso glutamatérgico (Taylor, Wassle, 1995; Zhou, Fain, 1995; Peters, Masland, 1996).

Uma célula denominada de interplexiforme merece menção especial. Alguns pesquisadores classificaram estas células como uma classe adicional de neurônios da retina, mas outros acreditam que esta represente apenas um outro subtipo de célula amácrina. Seus 
corpos celulares localizam-se na INL, recebem impulsos apenas nos seus processos na IPL, mas liberam a maioria de seus impulsos sinápticos na OPL, portanto, parecem atuar centrifugamente transportando impulsos da IPL para a OPL. Em gatos, estas células realizam sinapses químicas com dendritos de células bipolares associadas à cones e células bipolares associadas à bastonetes (Kolb, West, 1977; Nakamura, McGuire e Sterling, 1980; McGuire, Stevens e Sterling, 1984; Cohen, Sterling, 1990b). Em macacos do Novo Mundo e em peixes, as células interplexiformes contêm dopamina, enquanto que, em gatos e coelhos contêm o GABA como neurotransmissor, apresentando provavelmente diferentes funções em diferentes espécies (Sterling, Demb, 2004).

\subsubsection{Células ganglionares}

Em retinas de mamíferos existem entre 10 a 15 tipos morfológicos diferentes de células ganglionares. As principais características que as distinguem são tamanho e padrão de ramificação de sua árvore dendrítica (Masland, 2001b; Rockhill et al., 2002).

Em primatas algumas células com campo de ação amplo são denominadas de “parasol” por causa de sua extensa árvore dendrítica ou células “M” por que se projetam para a camada magnocelular do núcleo geniculado lateral (NGL) (Perry, Oehler e Cowey, 1984; Watanabe, Rodieck, 1989). Entretanto, outros tipos de células ganglionares com campo de ação amplo também se projetam para a camada magnocelular do NGL, portanto, o termo "M" poderia incluir diversos tipos celulares (Kaplan, Shapley, 1982).

Em macacos-prego as células ganglionares $\mathrm{M}$ apresentam dendritos que se ramificam na porção mais interna da IPL e possuem corpos celulares significantemente maiores que às células ganglionares cujos dendritos se ramificam na porção mais externa da IPL, no meridiano temporal e para excentricidades $3 \mathrm{~mm}$ a partir da fóvea (Lima, Silveira e Perry, 1996). Neste primata, assim como primatas do Velho Mundo, estima-se que as células ganglionares M constituam 10\% da população total de células ganglionares (1 mm em relação à fóvea), entretanto, a proporção aumenta na retina periférica para cerca de 17\% (Silveira et al., 1989; Lima, Silveira e Perry, 1993; Silveira, Perry e Yamada, 1993; Lima, Silveira e Perry, 1996). 
Em retina de primatas as células parasol ou células ganglionares M são homólogas as células $\alpha$ de gatos (Dacey et al., 2003). As células $\alpha$ possuem corpo celular grande e árvore dendrítica esparsamente ramificada. Em retinas de gatos este tipo de célula ganglionar corresponde a cerca de 3\% da população de células ganglionares. Os corpos das células ganglionares $\alpha$ formam um mosaico regular e sua árvore dendrítica forra toda a retina sem deixar intervalos. O tamanho da árvore dendritíca e a densidade das células $\alpha$ mostram uma relação inversa ao longo da retina: na periferia a densidade é baixa, com árvores dendríticas grandes, enquanto que, na retina central a densidade das células é alta mas as árvores dendríticas são pequenas (Peichl, 1991).

Em retinas de primatas as células também são classificadas em ON e OFF, sendo células com campo de ação amplo (células fásicas) ou células com campo de ação restrito (células tônicas). As células com campo de ação restrito são denominadas células ganglionares midget (do inglês ou anãs). Na região central da retina a árvore dendrítica das células ganglionares midget recebe informações das células bipolares midget que por sua vez recebem impulsos de um único cone (Kolb, Dekorver, 1991; Calkins et al., 1994), já, na região periférica da retina esta arborização recebe impulsos de muitas células midget bipolares. As células ganglionares midget também são chamadas de células "P” pois se projetam para a camada parvocelular do NGL (Watanabe, Rodieck, 1989; Dacey, 1993).

As células ganglionares midget ou células $\mathrm{P}$ são as mais freqüentes em retina de primatas do velho mundo (70-80\%) (Perry, Oehler e Cowey, 1984), sendo homólogas as células $\beta$ de gatos. Na retina central sua árvore dendrítica é extremamente pequena, portanto, estas células realizam sinapses apenas com uma única célula bipolar midget (Kolb, Marshak, 2003). Estas células representam a acuidade do sistema visual de primatas sendo previamente mencionadas como células ganglionares seletivas à cones M e L (Dacey, 1993). Em relação à primatas do Novo Mundo (Cebus apella e Aotus azarae) um estudo realizado com marcador retrógrado inserido no nervo óptico, a biocitina, indica que as células $\mathrm{P}$ são as mais numerosas, representando uma população da mesma ordem encontrada em primatas de Velho Mundo (Silveira et al., 1994).

Em retinas de primatas existem ainda outras classes de células ganglionares, tais como, as células biestratificadas, que possuem campo de ação pequeno e dendritos que se ramificam em dois níveis diferentes da IPL. Existem evidências de que estas células enviam 
projeções para as camadas intercaladas do NGL, cuja função é associada ao canal de oponência de cor azul-amarelo (Dacey, 1993; Dacey, Lee, 1994; Lee et al., 1996). Ou ainda, uma classe de células, com campo de ação muito amplo, que se projeta para o colículo superior (CS) e complexo pré-tetal assim como também para o NGL (Perry, Cowey, 1984).

Diferentes técnicas são utilizadas para se demonstrar os mosaicos retinianos formados pelos diversos tipos de células ganglionares. As células biestratificadas foram demonstradas por injeções intracelulares (Vaney, 1994), as células delta foram demonstradas por injeções intracelulares e pela captação de serotonina (5-HT) (Dacey, 1989), células ganglionares que se projetam para o trato óptico acessório foram demonstradas por marcação retrógrada (Buhl, Peichl, 1986).

Além disto, existem células ganglionares que contêm melanopsina e se projetam para o núcleo supraquiasmático (NSQ) e para centros subcorticais como o complexo pré tetal (Berson, 2003). Estas células representam uma população esparsa, que corresponde a cerca de 1 a 3\% da população de células ganglionares. Estudos eletrofisiológicos revelaram que estas células além de receberem impulsos de cones e bastonetes por meio das células bipolares, também são sensíveis a luz, respondendo à sinais luminosos mesmo quando a transmissão sináptica na retina é bloqueada, sendo portanto relacionadas à modulação de ritmos circadianos e ao reflexo pupilar (Berson, Dunn e Takao, 2002; Berson, 2003; Hattar et al., 2006).

Cada um dos tipos de células ganglionares forma uma lâmina que cobre toda a retina com suas respectivas árvores dendríticas. Tal fato tem conseqüências importantes para o processamento visual. Após a transdução pelos fotorreceptores e transferência dos impulsos para IPL por células bipolares, pode-se estimular pelo menos uma célula ganglionar de qualquer um dos tipos existentes, sendo que, cada qual é responsável por um aspecto da informação contida no sinal luminoso (contraste, tamanho, movimento, comprimento e etc...) (Wassle, 2004).

Em adição as características sinápticas, todos os primatas antropóides, com exceção de macacos-coruja, possuem uma fóvea. A fóvea é caracterizada pelo deslocamento de corpos celulares em relação aos fotorreceptores e máxima acuidade em condições de alta luminosidade. O deslocamento de corpos celulares dos segmentos internos e externos dos 
fotorreceptores para margens da fóvea é possível pela presença das fibras de Henle, que conectam os elementos fotorreceptivos à corpos celulares (Hsu et al., 1998).

A fóvea também apresenta especializações anatômicas relevantes para a maximização da acuidade visual diurna, incluindo alta densidade de cones e praticamente ausência de vascularização. Em primatas do Novo mundo, incluindo macacos-prego, o comprimento da zona livre de bastonetes (considerada a área que apresenta menos do que 5 bastonetes por $\mathrm{mm}^{2}$ ) no meridiano naso temporal é de $0.5 \mathrm{~mm}$ (Franco et al., 2000).

Estas características potencializam a densidade dos elementos de transdução, portanto estão relacionadas à acuidade, e minimizam a dispersão e absorção indesejada de fótons (Barlow, 1981; Snodderly, Weinhaus, 1990). 


\subsection{Caracteristícas de vias sinápticas na retina}

A retina, como outras áreas encefálicas, contém um grande número de substâncias neuroativas, porém pouco se sabe sobre a ação da maioria destas substâncias, especialmente sobre os peptídeos, entretanto, é fato que o glutamato e a acetilcolina modulam vias excitatórias, enquanto que, o GABA e a glicina modulam vias inibitórias.

Vários estudos, demonstraram a distribuição de diversos receptores, por meio dos quais as substâncias neuroativas como, por exemplo, GABA e glicina, atuam na retina de mamíferos.

Os receptores ionotrópicos sensíveis ao GABA, assim como os receptores de glicina, são membros de uma super família de receptores que se unem à canais iônicos, sendo compostos por 5 subunidades estruturais que formam um poro condutor de CL ${ }^{-}$. O N-terminal dos canais ligantes tem um longo domínio extracelular contendo locais de ligação (ligandbinding sites). Acredita-se que o C-terminal atravesse a membrana celular e forme quatro segmentos transmembrânicos com um larga alça intracelular entre o terceiro e o quarto segmento transmembrânico (Seeburg et al., 1990; Sieghart, 1995; De Blas, 1996; McKernan, Whiting, 1996).

Existem 16 tipos diferentes de subunidades que formam a família dos receptores GABA $_{\mathrm{A}}: \alpha 1-6, \beta 1-3, \gamma 1-3, \delta, \varepsilon, \pi$ e $\theta$, com muitas variações das combinações destas subunidades. Pelas regras de combinação vários tipos diferentes de receptores podem ser formados, entretanto, algumas combinações prevalecem, enquanto, outras não existem. As combinações $\alpha 1 / \beta 2,3 / \gamma 2, \alpha 2 / \beta 3 / \gamma 2 ; \alpha 3 / \beta 3 / \gamma 2$ são as mais comumente encontradas, sendo a expressão destas subunidades regionalmente específica (Fritschy, Mohler, 1995; Pirker et al., 2000; Mohler, Fritschy e Rudolph, 2002; Fritschy, Brunig, 2003; Mohler, 2006). A subunidade $\delta$, restrita aos processos das células amácrinas colinérgicas, é a subunidade menos comum na retina e também em outras áreas encefálicas (Fritschy, Mohler, 1995). A ativação dos receptores $\mathrm{GABA}_{\mathrm{A}}$ pelo GABA pode ocorrer por moduladores, como barbitúricos e benzodiazepínicos ou, ser antagonizada pela bicuculina (Sieghart, 1995).

Os Receptores $\mathrm{GABA}_{\mathrm{C}}$ são compostos pelas subunidades $\rho$ 1-3, são insensíveis aos moduladores dos receptores $\mathrm{GABA}_{\mathrm{A}}$, como barbitúricos e benzodiazepínicos, além disto, são insensíveis ao antagonista bicuculina e não são ativados pelo baclofeno, agonista do receptor 
$\mathrm{GABA}_{\mathrm{B}}$ e, apresentam maior sensibilidade ao GABA (Bormann, Feigenspan, 1995; Johnston, 1996; Bormann, 2000). Entretanto, alguns autores definem estes receptores como uma classe de receptores $\mathrm{GABA}_{\mathrm{A}}$ homoligoméricos (Barnard et al., 1998).

Os Receptores glicinérgicos são compostos por 2 subunidades $\alpha$ e 3 subunidades $\beta$ (Grudzinska et al., 2005). Atualmente, quatro genes diferentes que codificam as subunidades dos receptores para glicina ( $\alpha 1-\alpha 4)$, e um gene que codifica a subunidade $\beta$ foram identificados em vertebrados. Arranjos alternativos também contribuem com a heterogeneidade das subunidades dos receptores glicinérgicos que se agrupam para formar um poro condutor de $\mathrm{Cl}^{-}$(Legendre, 2001; Lynch, 2004; Betz, Laube, 2006).

Os receptores glicinérgicos, via subunidade $\beta$, e isoformas dos receptores $\mathrm{GABA}_{\mathrm{A}}$ são agregados em terminais pós sinápticos sendo ancorados pela proteína citoplasmática gefirina (Sassoe-Pognetto et al., 1995; Kneussel et al., 1999; Kneussel, Engelkamp e Betz, 2001; Lynch, 2004).

Os receptores $\mathrm{GABA}_{\mathrm{C}}$ foram descritos pela primeira vez na retina por Polenzani et al. (1991), quando estes autores demonstraram a expressão do RNA mensageiro destes receptores em retinas de Xenopus oocytes (Polenzani, Woodward e Miledi, 1991). Existem evidências de que estes receptores são compostos por subunidades $\rho$ originalmente clonadas da biblioteca de cDNA de humanos (Cutting et al., 1991; Cutting et al., 1992). As subunidades $\rho 1$ e $\rho 2$, homólogas as subunidades $\rho$ de humanos, foram clonadas de aves (Albrecht, Darlison, 1995) e as subunidades $\rho 1$, $\rho 2$ e $\rho 3$ foram clonadas de ratos, mostrando alto grau de similaridade com a seqüência humana correspondente (Enz et al., 1995; Zhang et al., 1995).

Os receptores $\mathrm{GABA}_{\mathrm{C}}$ são encontrados predominantemente nos terminais axonais das células bipolares e em uma pequena população de células amácrinas (Greferath et al., 1994; Wassle et al., 1998; Vitanova et al., 2001). Em roedores, existem evidências de que estes receptores em células bipolares sejam formados por subunidades $\rho 1$ e $\rho 2$ (Enz et al., 1995; Zhang et al., 1995; Yeh, Grigorenko e Veruki, 1996).

Os receptores $\mathrm{GABA}_{\mathrm{A}}$ estão localizados nos dendritos de células amácrinas e células ganglionares e em terminais axonais das células bipolares, porém, em sinapses distintas daquelas onde se localizam os receptores GABA $_{C}$ (Koulen et al., 1997; Koulen et al., 1998). 
Assim, estes dois receptores estariam estrategicamente posicionados para regular a liberação de transmissores pelas células bipolares (Lukasiewicz et al., 2004).

As propriedades funcionais dos receptores, incluindo a sensibilidade ao GABA e o limiar de dessensibilização, variam de acordo com as combinações das subunidades que compõem os receptores gabaérgicos. Estas subunidades podem ser identificadas preferencialmente em alguns tipos celulares, por exemplo, células amácrinas colinérgicas contêm a subunidade $\alpha 2$ do receptor $\mathrm{GABA}_{\mathrm{A}}$ (Wassle et al., 1998), enquanto que, a subunidade $\alpha 4$ é encontrada em células ganglionares (Khan et al., 1996) e a subunidade $\alpha 6$ em ambos os tipos celulares, células amácrinas e células ganglionares (Gutierrez, Khan e De Blas, 1996).

Normalmente os receptores gabaérgicos e glicinérgicos são expressos em diferentes sinapses, entretanto, em algumas regiões do SNC, como na medula espinal, podem ocorrer colocalizações das subunidades de diferentes receptores no mesmo poro condutor de $\mathrm{Cl}^{-}$. $\mathrm{Na}$ medula espinal os receptores $\mathrm{GABA}_{\mathrm{A}}$ e os receptores de glicina podem ser agregados em sinapses entre interneurônios inibitórios e motoneurônios (Todd, 1996; Todd et al., 1996; Alvarez et al., 1997; Dumoulin et al., 2000; Geiman, Knox e Alvarez, 2000; Geiman et al., 2002) e o GABA e a glicina podem ser liberados pela mesma vesícula no terminal pré sináptico (Jonas, Bischofberger e Sandkuhler, 1998; Keller et al., 2001).

Na retina de mamíferos o GABA e a glicina são liberados por diferentes tipos de células amácrinas, e a distribuição celular dos receptores $\mathrm{GABA}_{\mathrm{A}}, \mathrm{GABA}_{\mathrm{C}}$ e receptores de glicina são distintos (Koulen et al., 1996; Wassle et al., 1998; Grunert, 1999; Marc, Jones, 2002). Estudos in vitro sugerem a existência de receptores heteroméricos funcionais compostos por diferentes subunidades dos receptores $G_{A B A}, G A B A_{C}$ e de receptores de glicina (Pan et al., 2000; Ekema, Zheng e Lu, 2002; Pan, Qian, 2005).

A habilidade das subunidades dos receptores $\mathrm{GABA}_{\mathrm{A}}, \mathrm{GABA}_{\mathrm{C}}$ e de glicina se agruparem in vitro levanta a possibilidade de que certos receptores heteroméricos também possam existir in vivo em diversas regiões do SNC, inclusive na retina. 


\subsection{Projeções retinianas}

As principais vias retinianas até o córtex em primatas, e outras espécies, originam-se de classes específicas de células ganglionares na retina (Yamada, Silveira e Perry, 1996). A via retiniana passa pelo núcleo talâmico NGL e segue para o córtex visual primário, também denominado de V1 ou córtex estriado. Esta via é particularmente bem desenvolvida nos primatas, em comparação com as demais ordens de mamíferos, e está relacionada com a habilidade visual de discriminar e reconhecer objetos (Yamada, 1995).

O NGL é constituído de múltiplas camadas, das quais as maiores subdivisões podem ser distinguidas por suas características anatômicas e fisiológicas. As células ganglionares $\mathrm{M}$ enviam impulsos para as camadas magnocelulares do NGL conduzindo sinais luminosos, enquanto que, as células ganglionares $\mathrm{P}$ enviam impulsos para as camadas parvocelulares, e estão relacionadas a informações sobre oponência de cor vermelho-verde e sinais luminosos com contraste alto (Wiesel, Hubel, 1966; De Monasterio, Gouras, 1975; de Monasterio, 1978a; b; Leventhal, Rodieck e Dreher, 1981; Perry, Oehler e Cowey, 1984; Lee, Martin e Valberg, 1988; Lee et al., 1990).

Em primatas do novo mundo, o NGL é formado por uma camada superficial "S" (ventral), compreendendo células pequenas; duas camadas magnocelulares, compreendendo células grandes e as mais dorsais denominadas parvocelulares, compreendendo células de tamanho médio, arranjadas em quatro camadas. Além disto, zonas intralaminares, compostas por células pequenas separam a maioria destas camadas, com exceção das camadas superficiais e da parte rostral das camadas parvocelulares. As camadas magnocelulares e parvocelulares internas recebem projeções de células da retina ipsilateral, enquanto que, as camadas externas recebem projeções contralaterais; sendo que, quando o padrão de distribuição de projeções retinianas é aparente nas camadas $S$, as projeções contralaterais são internas em relação as projeções ipsilaterais (Kaas, Huerta, 1988).

Em mamíferos não primatas, usa-se a nomenclatura "núcleo geniculado lateral dorsal” e "núcleo geniculado lateral ventral” para distinguir duas porções do núcleo, que são separadas por um grupamento celular denominado folheto intergeniculado (FIG). Em primatas, entretanto, há controvérsias sobre a existência desta divisão, o homólogo ao núcleo geniculado lateral ventral seria o chamado núcleo pré geniculado (PGN) o qual se situa dorsalmente ao NGL e pode ser dividido em duas camadas, uma interna contendo células 
pequenas, que recebe impulsos do olho contralateral, além de uma porção restrita que também recebe impulsos do olho ipsilateral, e outra camada externa contendo células maiores, que recebe projeções corticais (Kaas, Huerta, 1988; Yamada, 1995). A parte interna deste núcleo compreende uma população de células caracterizadas pela imunorreatividade ao NPY (NPYIR) que se projetam para o NSQ (Moore, 1989), sendo estas células separadas da camada parvocelular do NGL por uma densa cápsula de fibras, portanto, existe a sugestão de que o PGN represente em primatas o homólogo ao FIG de roedores, mas ainda há discussões sobre a existência do trato geniculohipotâlamico (TGH) em primatas (Moore, 1993).

Em primatas alguns neurônios do PGN respondem a estímulos luminosos, e a maioria exibe mudanças na atividade em relação ao movimento dos olhos (Buttner, Fuchs, 1973). As diversas conexões deste núcleo sugerem que possa estar envolvido em uma série de funções, por exemplo, participação no controle de ritmos circadianos devido suas projeções para o NSQ, e funções oculomotoras devido suas conexões com o CS e ponte (Brauer et al., 1984).

Estima-se que cerca de 10\% das células ganglionares projetam-se com distribuição caracteristíca para as camadas superficiais do CS em primatas (Perry, Cowey, 1984). Este núcleo recebe impulsos de ambos os olhos, sendo a distribuição das projeções ipsi e contralaterais similar, entretanto, a projeção ipsilateral tende a ser um pouco mais difusa e terminar em níveis adjacentes porém inferiores as projeções contralaterais. Além disto, a região rostrolateral do CS, na qual a visão central é representada, apresenta terminações retinianas esparsas (Kaas, Huerta, 1988).

O CS, localizado no teto do mesencéfalo, se apresenta como estrutura laminada, contendo em geral sete camadas e constitui importante estação visual subcortical. Este núcleo desempenha dupla função na visão, participando da transmissão da informação visual para estruturas talâmicas associadas com a percepção visual e da transformação da informações visuais, em sinais de controle dos movimentos da cabeça e dos olhos (Kaas, Huerta, 1988).

As camadas do CS são arranjadas concentricamente no aspecto dorsolateral da substância cinzenta, sendo numeradas consecutivamente da camada mais superficial à camada mais profunda (camada I a VII). As camadas I (stratum zonale), III (stratum opticum), V (stratum album intermediale) e VII (stratum album profundum) são compostas por fibras, e as camadas II (stratum griseum superficiale), IV (stratum griseum intermediale) e VI (stratum 
griseum profundum) são celulares. Estas camadas podem ainda ser subdivididas em relação à citoarquitetura, características histoquímicas, e suas conexões (Kaas, Huerta, 1988).

Outras áreas encefálicas que recebem projeções retinianas estão envolvidas com aspectos regulatórios e autonômicos do comportamento visual. Dentre estas estruturas estão o complexo pré-tetal, formado por um conjunto de núcleos situados no tronco encefálico, relacionados à via do reflexo pupilar à luz e ao nistagmo optocinético (Hutchins, Weber, 1985).

O complexo pré-tetal foi estudado anatomicamente no macaco de cheiro (Saimiri sciureus) no qual foram identificados cinco núcleos: pré-tetal anterior (APN), núcleo pré-tetal posterior (PPT), núcleo pré-tetal medial (MPN), núcleo do trato óptico (NOT) e núcleo olivar pré-tetal (OPN) (Hutchins, Weber, 1985; Weber, 1985). O NOT e o OPN recebem densa projeção bilateral, sendo a projeção para os demais núcleos principalmente contralateral e consideravelmente menor em relação as projeções para os núcleos do trato óptico e olivar prétetal.

Assim como o complexo pré-tetal, o sistema óptico acessório abrange núcleos retinocipientes pequenos (Simpson, 1984; Weber, 1985), relacionados à atividade visuomotora. Sendo estes: núcleo terminal dorsal (DTN), que em primatas está localizado na região lateral do teto do mesencéfalo caudal ao núcleo geniculado medial e ventrolateralmente ao braço do CS; núcleo terminal medial (MTN), localizado no tegumento mesencefálico medialmente ao pedúnculo cerebral, rostral à saída do nervo oculomotor e núcleo terminal lateral (LTN), localizado entre o braço do colículo inferior e o aspecto ventromedial do núcleo geniculado medial e núcleo intersticial do fascículo superior posterior (Lin, Giolli, 1979; Blanks et al., 1995).

Embora existam poucos dados sobre as conexões aferentes e as funções do sistema óptico acessório, este parece modular atividades visuomotoras. Em coelhos o sistema óptico acessório inerva a região do núcleo olivar inferior que, por sua vez, inerva o lobo flóculo nodular do cerebelo (Maekawa, Takeda, 1979), além de enviar projeções para os núcleos do trato óptico e vestibulares. Estudos fisiológicos sugerem que os núcleos do sistema óptico acessório atuem na estabilização da imagem na retina (Simpson, 1984). 
As projeções retinianas também são importantes por enviarem informações para estruturas do sistema de temporização circadiana, responsável pela geração e modulação dos ritmos circadianos. Este sistema é composto por osciladores, vias de entrada sincornizadoras e vias para efetores comportamentais (Rusak, Zucker, 1979; Meijer, Rietveld, 1989; Morin, 1994; Turek, 1994).

A existência da principal via sincronizadora deste sistema, o trato retinohipotalâmico (TRH), foi confirmada em estudos realizados em várias espécies de mamíferos, incluindo primatas do Velho e do Novo mundo (Hendrickson, Wagoner e Cowan, 1972; Moore, Lenn, 1972; Moore, 1973; 1993; Costa et al., 1999; Cavalcante, 2000).

As descrições originais do TRH, baseadas em técnicas de auto-radiografia, descrevem projeções da retina, no hipotálamo, exclusivamente para o NSQ (Hendrickson, Wagoner e Cowan, 1972; Moore, 1973), entretanto, a utilização de traçadores neurais mais sensíveis, tais como toxina colérica, tornou evidente a existência de projeções para outras regiões do hipotálamo como, por exemplo, para área pré-óptica medial, área pré-óptica lateral, núcleo pré-óptico mediano, núcleo paraventricular, área hipotalâmica anterior, área hipotalâmica lateral, núcleo supra-óptico, área retroquiasmática e zona subparaventricular (Levine et al., 1991; Youngstrom, Weiss e Nunez, 1991; Moore, 1993; Costa et al., 1999; Cavalcante, 2000).

Projeções ópticas adicionais para estruturas usualmente não consideradas como parte do sistema visual também foram descritas em várias espécies de mamíferos, tais como, o núcleo pericentral do colículo inferior em gatos, ratos e macaco Rhesus (Itaya, Van Hoesen, 1982; Paloff et al., 1985), núcleo ântero dorsal do tálamo no musaranho das árvores (Conrad, Stumpf, 1975), núcleos da rafe em gatos e ratos (Foote, Taber-Pierce e Edwards, 1978; Shen, Semba, 1994) e até mesmo estruturas telencefálicas, tais como o tubérculo olfatório e núcleo da banda diagonal de Broca, em hamster, ratos, coelhos, ouriços, preguiças, morcegos, tamanduás, Spalax ehrenberghi e Macaca fascicularis (Cooper, Mick e Magnin, 1989; Levine et al., 1991; Youngstrom, Weiss e Nunez, 1991). 


\subsection{Macacos-prego}

Macacos-prego, cujo nome científico é Cebus apella, da família Cebidae, são primatas do Novo Mundo de tamanho médio comparados em muitos aspectos com o menor primata de Velho Mundo Macaca fascicularis. Baseado no tamanho de seu encéfalo, no padrão de distribuição dos sulcos encefálicos e hábitos diurnos os macacos-prego apresentam maior similiaridade com primatas do Velho Mundo do que macacos-coruja (Aotus trivirgatus) outro primata do Novo Mundo que apresenta hábitos noturnos, encéfalo menor e menor número de giros encefálicos (Allman, Kaas, 1971; Gattass, Gross, 1981; Gattass, Gross e Sandell, 1981; Gattass, Sousa e Rosa, 1987; Gattass, Sousa e Gross, 1988; Rosa, Sousa e Gattass, 1988; Fiorani et al., 1989).

É o mais comum dos macacos sul-americanos, sendo, provavelmente um dos mais resistentes. Muito ativo, sua distribuição geográfica abrange o leste da Colômbia, leste do Peru, todo o Brasil e também Bolívia. Seu tamanho, da cabeça ao final da corpo, varia de 30 a 56cm; sua cauda mede entre 30 a 55cm. Vivem em diferentes tipos de matas desde o nível do mar até 2700 metros de altitude, sempre em grupos. Possuem cauda prêensil, utilizando-a como um membro auxiliar na locomoção. Em geral é um macho adulto que comanda o bando, sendo que, as vezes o grupo tem mais fêmeas que machos. Comunicam-se com uma variedade muito grande de sons. As fêmeas têm normalmente um filhote pôr vez, depois de uma gestação de aproximadamente 6 meses, este fica preso no peito da mãe depois de nascer, passando depois de algum tempo para as costas.

Para a compreensão de aspectos referentes ao sistema visual, vários estudos são realizados em primatas. Características da retina, de núcleos do sistema visual primário e córtex visual são amplamente pesquisados principalmente no que se refere à primatas do Velho Mundo. Macacos-prego por se adaptarem bem em cativeiro, reproduzindo com certa facilidade, constituem um modelo experimental muito utilizado, vários trabalhos reportam dados relativos a morfologia de fotorreceptores (Andrade da Costa, Hokoc, 2000; Franco et al., 2000), células horizontais (dos Reis et al., 2002; Dos Santos et al., 2005) e caracteristícas fisiológicas e morfológicas de células ganglionares nesta espécie (Silveira, Picanco-Diniz e Oswaldo-Cruz, 1989; Lima, Silveira e Perry, 1993; Silveira, Perry e Yamada, 1993; Lima, Silveira e Perry, 1996; Yamada et al., 1996; Yamada, Silveira e Perry, 1996; Lee et al., 2000; Yamada et al., 2001). 
Uma das características marcantes que excita a curiosidade em relação a diversas características do sistema nervoso de macacos-prego, quer no que se refere ao sistema visual ou no que se refere a outros sistemas neurais, trata do fato de que os encéfalos de macacosprego apresentam giros encefálicos, além de se tratar de um animal de hábitos diurnos, o que permite a comparação evolutiva destes sistemas com os sistemas dos modelos mais comumente utilizados, roedores de hábitos noturnos.

Quando comaparados os estudos existentes na literatura entre as diversas espécies já analisadas, são observados dados contorversos no que se refere ao padrão de distribuição de terminais retinianos.

Portanto, o presente estudo utiliza como modelo experimental macacos-prego, para descrição de características gerais do sistema visual, tais como: a busca de marcadores para a identificação dos grupamentos celulares da retina, a análise da distribuição de receptores da via inibitória na retina, classicamente já descrita em espécies não primatas, e ainda a análise das áreas retinorecipientes no encéfalo desta espécie. Esses estudos poderão contribuir para correlação funcional de tipos e grupamentos celulares específicos, questionando a participação dos mesmos na modulação de sinais luminosos em primata de hábitos diurno. 


\section{CONCLUSÕES}

Embora similaridades tenham sido encontradas no mapeamento dos diferentes tipos celulares e de receptores na retina de macacos-prego com outras espécies já descritas, os dados obtidos sugerem que algumas caracteristicas químicas podem variar principalmente quando comparamos primatas e roedores, assim generalizações de resultados em espécies diferentes devem ser evitados.

Diversos marcadores foram definidos para o reconhecimento de células da retina de macacos-prego permitindo que futuros estudos fisiológicos sejam realizados.

Receptores heteroméricos compostos por subunidades dos receptores $\mathrm{GABA}_{\mathrm{C}} \mathrm{e}$ subunidade $\mathrm{GABA}_{\mathrm{A}} \gamma 2$ podem representar uma especialização sináptica em retinas de primatas do Novo Mundo.

As projeções retinianas para os núcleos do sistema visual primário e sistema óptico acessório estão distribuídas de forma semelhante ao descrito na literatura para outras espécies.

As projeções para o sistema de temporização circadiana reinforçam a existência de diferenças no mecanismo envolvido na regulação de ritmos circadianos entre diferentes espécies de mamíferos, Além disto, projeções ópticas adicionais sugerem modulação indireta de estruturas do sistema visual.

Projeções recíprocas entre a retina e o núcleo DR possivelmente formam uma importante via pela qual a luz ambiental pode influenciar a atividade de neurônios deste núcleo, com efeitos potenciais em uma grande gama de circuitos neurais e comportamentais. Tais circuitos podem em primatas, assim como em roedores, estarem relacionados ao sistema de temporização circadiana e relacionar o sistema serotonérgico a informações fóticas diretas. 


\section{REFERENCIAS}

Agarwala S, Petry HM, May JG, 3rd. Retinal projections in the ground squirrel (Citellus tridecemlineatus). Vis Neurosci. 1989;3:537-49.

Ahnelt P, Kolb H. Horizontal cells and cone photoreceptors in human retina: a Golgi-electron microscopic study of spectral connectivity. J Comp Neurol. 1994a;343:406-27.

Ahnelt P, Kolb H. Horizontal cells and cone photoreceptors in primate retina: a Golgi-light microscopic study of spectral connectivity. J Comp Neurol. 1994b;343:387-405.

Albrecht BE, Darlison MG. Localization of the rho 1- and rho 2-subunit messenger RNAs in chick retina by in situ hybridization predicts the existence of gamma-aminobutyric acid type C receptor subtypes. Neurosci Lett. 1995;189:155-8.

Allman JM, Kaas JH. Representation of the visual field in striate and adjoining cortex of the owl monkey (Aotus trivirgatus). Brain Res. 1971;35:89-106.

Alvarez FJ, Dewey DE, Harrington DA, Fyffe RE. Cell-type specific organization of glycine receptor clusters in the mammalian spinal cord. J Comp Neurol. 1997;379:150-70.

Andrade da Costa BL, Hokoc JN. Photoreceptor topography of the retina in the New World monkey Cebus apella. Vision Res. 2000;40:2395-409.

Andrade da Costa BL, Hokoc JN. Coexistence of GAD-65 and GAD-67 with tyrosine hydroxylase and nitric oxide synthase in amacrine and interplexiform cells of the primate, Cebus apella. Vis Neurosci. 2003;20:153-63.

Angelucci A, Clasca F, Sur M. Anterograde axonal tracing with the subunit B of cholera toxin: a highly sensitive immunohistochemical protocol for revealing fine axonal morphology in adult and neonatal brains. J Neurosci Methods. 1996;65:101-12.

Awatramani GB, Slaughter MM. Origin of transient and sustained responses in ganglion cells of the retina. J Neurosci. 2000;20:7087-95.

Barlow HB. The Ferrier Lecture, 1980. Critical limiting factors in the design of the eye and visual cortex. Proc R Soc Lond B Biol Sci. 1981;212:1-34.

Barnard EA, Skolnick P, Olsen RW, Mohler H, Sieghart W, Biggio G et al. International Union of Pharmacology. XV. Subtypes of gamma-aminobutyric acidA receptors: classification on the basis of subunit structure and receptor function. Pharmacol Rev. 1998;50:291-313.

Baylor DA, Fuortes MG, O'Bryan PM. Receptive fields of cones in the retina of the turtle. J Physiol. 1971;214:265-94.

Benke D, Honer M, Michel C, Mohler H. GABAA receptor subtypes differentiated by their gamma-subunit variants: prevalence, pharmacology and subunit architecture. Neuropharmacology. 1996;35:1413-23. 
Berry MJ, Warland DK, Meister M. The structure and precision of retinal spike trains. Proc Natl Acad Sci U S A. 1997;94:5411-6.

Berson DM. Strange vision: ganglion cells as circadian photoreceptors. Trends Neurosci. 2003;26:314-20.

Berson DM, Dunn FA, Takao M. Phototransduction by retinal ganglion cells that set the circadian clock. Science. 2002;295:1070-3.

Betz H, Laube B. Glycine receptors: recent insights into their structural organization and functional diversity. J Neurochem. 2006;97:1600-10.

Billet S, Cant NB, Hall WC. Cholinergic projections to the visual thalamus and superior colliculus. Brain Res. 1999;847:121-3.

Blanks RH, Clarke RJ, Lui F, Giolli RA, Van Pham S, Torigoe Y. Projections of the lateral terminal accessory optic nucleus of the common marmoset (Callithrix jacchus). J Comp Neurol. 1995;354:511-32.

Bloomfield SA. Relationship between receptive and dendritic field size of amacrine cells in the rabbit retina. J Neurophysiol. 1992;68:711-25.

Bohlhalter S, Weinmann O, Mohler H, Fritschy JM. Laminar compartmentalization of GABAA-receptor subtypes in the spinal cord: an immunohistochemical study. J Neurosci. 1996;16:283-97.

Boos R, Schneider H, Wassle H. Voltage- and transmitter-gated currents of all-amacrine cells in a slice preparation of the rat retina. J Neurosci. 1993;13:2874-88.

Bormann J. The 'ABC' of GABA receptors. Trends Pharmacol Sci. 2000;21:16-9.

Bormann J, Feigenspan A. GABAC receptors. Trends Neurosci. 1995;18:515-9.

Boue-Grabot E, Roudbaraki M, Bascles L, Tramu G, Bloch B, Garret M. Expression of GABA receptor rho subunits in rat brain. J Neurochem. 1998;70:899-907.

Bowery NG, Smart TG. GABA and glycine as neurotransmitters: a brief history. $\mathrm{Br} \mathrm{J}$ Pharmacol. 2006;147 Suppl 1:S109-19.

Boycott BB. Horizontal cells of mammalian retinae. Neurosci Res Suppl. 1988;8:S97-111.

Boycott BB, Hopkins JM. Cone bipolar cells and cone synapses in the primate retina. Vis Neurosci. 1991;7:49-60.

Boycott BB, Hopkins JM, Sperling HG. Cone connections of the horizontal cells of the rhesus monkey's retina. Proc R Soc Lond B Biol Sci. 1987;229:345-79.

Boycott BB, Kolb H. The horizontal cells of the rhesus monkey retina. J Comp Neurol. 1973;148:115-39. 
Boycott BB, Wassle H. Morphological Classification of Bipolar Cells of the Primate Retina. Eur J Neurosci. 1991;3:1069-1088.

Brandstatter JH, Koulen P, Wassle H. Diversity of glutamate receptors in the mammalian retina. Vision Res. 1998;38:1385-97.

Brauer K, Schober W, Leibnitz L, Werner L, Luth HJ, Winkelmann E. The ventral lateral geniculate nucleus of the albino rat morphological and histochemical observations. J Hirnforsch. 1984;25:205-36.

Brunken WJ, Daw NW. The effects of serotonin agonists and antagonists on the response properties of complex ganglion cells in the rabbit's retina. Vis Neurosci. 1988;1:181-8.

Buhl EH, Peichl L. Morphology of rabbit retinal ganglion cells projecting to the medial terminal nucleus of the accessory optic system. J Comp Neurol. 1986;253:163-74.

Buttner-Ennever JA, Cohen B, Horn AK, Reisine H. Efferent pathways of the nucleus of the optic tract in monkey and their role in eye movements. J Comp Neurol. 1996;373:90-107.

Buttner U, Fuchs AF. Influence of saccadic eye movements on unit activity in simian lateral geniculate and pregeniculate nuclei. J Neurophysiol. 1973;36:127-41.

Cagampang FR, Inouye ST. Diurnal and circadian changes of serotonin in the suprachiasmatic nuclei: regulation by light and an endogenous pacemaker. Brain Res. 1994;639:175-9.

Calkins DJ, Schein SJ, Tsukamoto Y, Sterling P. M and L cones in macaque fovea connect to midget ganglion cells by different numbers of excitatory synapses. Nature. 1994;371:70-2.

Calkins DJ, Sterling P. Absence of spectrally specific lateral inputs to midget ganglion cells in primate retina. Nature. 1996;381:613-5.

Card JP, Moore RY. Organization of lateral geniculate-hypothalamic connections in the rat. J Comp Neurol. 1989;284:135-47.

Casini G, Brecha NC, Bosco L, Rickman DW. Developmental expression of neurokinin-1 and neurokinin-3 receptors in the rat retina. J Comp Neurol. 2000;421:275-87.

Casini G, Rickman DW, Brecha NC. AII amacrine cell population in the rabbit retina: identification by parvalbumin immunoreactivity. J Comp Neurol. 1995;356:132-42.

Cavalcante JS. Projeções retinianas e distribuição de proteínas ligantes de cálcio nas áreas retino-recipientes do hipotálamo do sagüi (Callithrix jacchus). [grau (Mestrado)]. (Brasil): Instituto de Ciências Biomédicas da Universidade de São Paulo; 2000.

Cavalcante JS, Alves AS, Costa MS, Britto LR. Differential distribution of afferents containing serotonin and neuropeptide $\mathrm{Y}$ within the marmoset suprachiasmatic nucleus. Brain Res. 2002;927:200-3. 
Cavalcante JS, Costa MS, Santee UR, Britto LR. Retinal projections to the midline and intralaminar thalamic nuclei in the common marmoset (Callithrix jacchus). Brain Res. 2005;1043:42-7.

Chan TL, Goodchild AK, Martin PR. The morphology and distribution of horizontal cells in the retina of a New World monkey, the marmoset Callithrix jacchus: a comparison with macaque monkey. Vis Neurosci. 1997;14:125-40.

Chan TL, Grunert U. Horizontal cell connections with short wavelength-sensitive cones in the retina: a comparison between New World and Old World primates. J Comp Neurol. 1998;393:196-209.

Chan TL, Martin PR, Clunas N, Grunert U. Bipolar cell diversity in the primate retina: morphologic and immunocytochemical analysis of a new world monkey, the marmoset Callithrix jacchus. J Comp Neurol. 2001;437:219-39.

Chan TL, Martin PR, Grunert U. Immunocytochemical identification and analysis of the diffuse bipolar cell type DB6 in macaque monkey retina. Eur J Neurosci. 2001;13:829-32.

Chebib M. GABAC receptor ion channels. Clin Exp Pharmacol Physiol. 2004;31:800-4.

Chun MH, Grunert U, Martin PR, Wassle H. The synaptic complex of cones in the fovea and in the periphery of the macaque monkey retina. Vision Res. 1996;36:3383-95.

Cohen AI. Some electron microscopic observations on inter-receptor contacts in the human and macaque retinae. J Anat. 1965;99:595-610.

Cohen E, Sterling P. Convergence and divergence of cones onto bipolar cells in the central area of cat retina. Philos Trans R Soc Lond B Biol Sci. 1990a;330:323-8.

Cohen E, Sterling P. Demonstration of cell types among cone bipolar neurons of cat retina. Philos Trans R Soc Lond B Biol Sci. 1990b;330:305-21.

Cohen ED. Voltage-gated calcium and sodium currents of starburst amacrine cells in the rabbit retina. Vis Neurosci. 2001;18:799-809.

Conrad CD, Stumpf WE. Direct visual input to the limbic system: crossed retinal projections to the nucleus anterodorsalis thalami in the tree shrew. Exp Brain Res. 1975;23:141-9.

Cooper HM, Herbin M, Nevo E. Ocular regression conceals adaptive progression of the visual system in a blind subterranean mammal. Nature. 1993;361:156-9.

Cooper HM, Mick G, Magnin M. Retinal projection to mammalian telencephalon. Brain Res. 1989;477:350-7.

Costa MS, Santee UR, Cavalcante JS, Moraes PR, Santos NP, Britto LR. Retinohypothalamic projections in the common marmoset (Callithrix jacchus): A study using cholera toxin subunit B. J Comp Neurol. 1999;415:393-403. 
Crooks J, Kolb H. Localization of GABA, glycine, glutamate and tyrosine hydroxylase in the human retina. J Comp Neurol. 1992;315:287-302.

Cutting GR, Curristin S, Zoghbi H, O'Hara B, Seldin MF, Uhl GR. Identification of a putative gamma-aminobutyric acid (GABA) receptor subunit rho2 cDNA and colocalization of the genes encoding rho2 (GABRR2) and rho1 (GABRR1) to human chromosome 6q14-q21 and mouse chromosome 4. Genomics. 1992;12:801-6.

Cutting GR, Lu L, O'Hara BF, Kasch LM, Montrose-Rafizadeh C, Donovan DM et al. Cloning of the gamma-aminobutyric acid (GABA) rho 1 cDNA: a GABA receptor subunit highly expressed in the retina. Proc Natl Acad Sci U S A. 1991;88:2673-7.

da Costa BL, Hokoc JN, Pinaud RR, Gattass R. GABAergic retinocollicular projection in the New World monkey Cebus apella. Neuroreport. 1997;8:1797-802.

Dacey D, Packer OS, Diller L, Brainard D, Peterson B, Lee B. Center surround receptive field structure of cone bipolar cells in primate retina. Vision Res. 2000;40:1801-11.

Dacey DM. Monoamine-accumulating ganglion cell type of the cat's retina. J Comp Neurol. 1989;288:59-80.

Dacey DM. The mosaic of midget ganglion cells in the human retina. J Neurosci. 1993;13:5334-55.

Dacey DM, Lee BB. The 'blue-on' opponent pathway in primate retina originates from a distinct bistratified ganglion cell type. Nature. 1994;367:731-5.

Dacey DM, Lee BB, Stafford DK, Pokorny J, Smith VC. Horizontal cells of the primate retina: cone specificity without spectral opponency. Science. 1996;271:656-9.

Dacey DM, Peterson BB, Robinson FR, Gamlin PD. Fireworks in the primate retina: in vitro photodynamics reveals diverse LGN-projecting ganglion cell types. Neuron. 2003;37:15-27.

Dacheux RF, Raviola E. Physiology of HI horizontal cells in the primate retina. Proc R Soc Lond B Biol Sci. 1990;239:213-30.

De Blas AL. Brain GABAA receptors studied with subunit-specific antibodies. Mol Neurobiol. 1996;12:55-71.

de Monasterio FM. Center and surround mechanisms of opponent-color X and Y ganglion cells of retina of macaques. J Neurophysiol. 1978a;41:1418-34.

de Monasterio FM. Properties of concentrically organized X and Y ganglion cells of macaque retina. J Neurophysiol. 1978b;41:1394-1417.

De Monasterio FM, Gouras P. Functional properties of ganglion cells of the rhesus monkey retina. J Physiol. 1975;251:167-95. 
Deans MR, Volgyi B, Goodenough DA, Bloomfield SA, Paul DL. Connexin36 is essential for transmission of rod-mediated visual signals in the mammalian retina. Neuron. 2002;36:70312.

Demb JB, Pugh EN. Connexin36 forms synapses essential for night vision. Neuron. 2002;36:551-3.

DeVries SH. Bipolar cells use kainate and AMPA receptors to filter visual information into separate channels. Neuron. 2000;28:847-56.

DeVries SH, Baylor DA. An alternative pathway for signal flow from rod photoreceptors to ganglion cells in mammalian retina. Proc Natl Acad Sci U S A. 1995;92:10658-62.

DeVries SH, Schwartz EA. Kainate receptors mediate synaptic transmission between cones and 'Off' bipolar cells in a mammalian retina. Nature. 1999;397:157-60.

dos Reis JW, de Carvalho WA, Saito CA, Silveira LC. Morphology of horizontal cells in the retina of the capuchin monkey, Cebus apella: how many horizontal cell classes are found in dichromatic primates? J Comp Neurol. 2002;443:105-23.

Dos Santos SN, Dos Reis JW, Da Silva Filho M, Kremers J, Silveira LC. Horizontal cell morphology in nocturnal and diurnal primates: a comparison between owl-monkey (Aotus) and capuchin monkey (Cebus). Vis Neurosci. 2005;22:405-15.

Dowling JE. Retina. In: Encyclopedia of the Human Brain. Elsevier Science; 2002, 217-235.

Dowling JE, Boycott BB. Organization of the primate retina: electron microscopy. Proc R Soc Lond B Biol Sci. 1966;166:80-111.

Dumoulin A, Levi S, Riveau B, Gasnier B, Triller A. Formation of mixed glycine and GABAergic synapses in cultured spinal cord neurons. Eur J Neurosci. 2000;12:3883-92.

Ehinger B, Hansson C, Tornqvist K. 5-Hydroxytryptamine in the retina of some mammals. Exp Eye Res. 1981;33:663-72.

Ekema GM, Zheng W, Lu L. Interaction of GABA receptor/channel rho(1) and gamma(2) subunit. Invest Ophthalmol Vis Sci. 2002;43:2326-33.

Enz R, Brandstatter JH, Hartveit E, Wassle H, Bormann J. Expression of GABA receptor rho 1 and rho 2 subunits in the retina and brain of the rat. Eur J Neurosci. 1995;7:1495-501.

Enz R, Brandstatter JH, Wassle H, Bormann J. Immunocytochemical localization of the GABAc receptor rho subunits in the mammalian retina. J Neurosci. 1996;16:4479-90.

Enz R, Cutting GR. Molecular composition of GABAC receptors. Vision Res. 1998;38:143141.

Ericson H, Blomqvist A. Tracing of neuronal connections with cholera toxin subunit B: light and electron microscopic immunohistochemistry using monoclonal antibodies. J Neurosci Methods. 1988;24:225-35. 
Erisir A, Van Horn SC, Bickford ME, Sherman SM. Immunocytochemistry and distribution of parabrachial terminals in the lateral geniculate nucleus of the cat: a comparison with corticogeniculate terminals. J Comp Neurol. 1997;377:535-49.

Euler T, Detwiler PB, Denk W. Directionally selective calcium signals in dendrites of starburst amacrine cells. Nature. 2002;418:845-52.

Euler T, Masland RH. Light-evoked responses of bipolar cells in a mammalian retina. J Neurophysiol. 2000;83:1817-29.

Euler T, Schneider H, Wassle H. Glutamate responses of bipolar cells in a slice preparation of the rat retina. J Neurosci. 1996;16:2934-44.

Euler T, Wassle H. Immunocytochemical identification of cone bipolar cells in the rat retina. $\mathrm{J}$ Comp Neurol. 1995;361:461-78.

Famiglietti EV. A new type of wide-field horizontal cell, presumably linked to blue cones, in rabbit retina. Brain Res. 1990;535:174-9.

Famiglietti EV, Jr., Kolb H. A bistratified amacrine cell and synaptic cirucitry in the inner plexiform layer of the retina. Brain Res. 1975;84:293-300.

Feigenspan A, Janssen-Bienhold U, Hormuzdi S, Monyer H, Degen J, Sohl G et al. Expression of connexin36 in cone pedicles and OFF-cone bipolar cells of the mouse retina. $\mathrm{J}$ Neurosci. 2004;24:3325-34.

Feigenspan A, Wassle H, Bormann J. Pharmacology of GABA receptor Cl- channels in rat retinal bipolar cells. Nature. 1993;361:159-62.

Fiorani M, Jr., Gattass R, Rosa MG, Sousa AP. Visual area MT in the Cebus monkey: location, visuotopic organization, and variability. J Comp Neurol. 1989;287:98-118.

Fischer F, Kneussel M, Tintrup H, Haverkamp S, Rauen T, Betz H et al. Reduced synaptic clustering of GABA and glycine receptors in the retina of the gephyrin null mutant mouse. $\mathrm{J}$ Comp Neurol. 2000;427:634-48.

Fite KV, Janusonis S. Retinal projection to the dorsal raphe nucleus in the Chilean degus (Octodon degus). Brain Res. 2001;895:139-45.

Fite KV, Janusonis S. Optic afferents to the parabrachial nucleus. Brain Res. 2002;943:9-14.

Fite KV, Janusonis S, Foote W, Bengston L. Retinal afferents to the dorsal raphe nucleus in rats and Mongolian gerbils. J Comp Neurol. 1999;414:469-84.

Fletcher EL, Koulen P, Wassle H. GABAA and GABAC receptors on mammalian rod bipolar cells. J Comp Neurol. 1998;396:351-65.

Foote WE, Taber-Pierce E, Edwards L. Evidence for a retinal projection to the midbrain raphe of the cat. Brain Res. 1978;156:135-40. 
Franco EC, Finlay BL, Silveira LC, Yamada ES, Crowley JC. Conservation of absolute foveal area in New World monkeys. A constraint on eye size and conformation. Brain Behav Evol. 2000;56:276-86.

Frazão R, Nogueira MI, Wassle H. Colocalization of synaptic GABA(C)-receptors with GABA (A)-receptors and glycine-receptors in the rodent central nervous system. Cell Tissue Res. 2007;330:1-15.

Frazão R, Pinato L, da Silva AV, Britto LR, Oliveira JA, Nogueira MI. Evidence of reciprocal connections between the dorsal raphe nucleus and the retina in the monkey Cebus apella. Neurosci Lett. 2008;430:119-23.

Freed MA, Smith RG, Sterling P. Rod bipolar array in the cat retina: pattern of input from rods and GABA-accumulating amacrine cells. J Comp Neurol. 1987;266:445-55.

Freed MA, Sterling P. The ON-alpha ganglion cell of the cat retina and its presynaptic cell types. J Neurosci. 1988;8:2303-20.

Fritschy JM, Brunig I. Formation and plasticity of GABAergic synapses: physiological mechanisms and pathophysiological implications. Pharmacol Ther. 2003;98:299-323.

Fritschy JM, Mohler H. GABAA-receptor heterogeneity in the adult rat brain: differential regional and cellular distribution of seven major subunits. J Comp Neurol. 1995;359:154-94.

Fulwiler CE, Saper CB. Subnuclear organization of the efferent connections of the parabrachial nucleus in the rat. Brain Res. 1984;319:229-59.

Gabriel R, Straznicky C. Immunocytochemical localization of parvalbumin- and neurofilament triplet protein immunoreactivity in the cat retina: colocalization in a subpopulation of AII amacrine cells. Brain Res. 1992;595:133-6.

Gastinger MJ, Bordt AS, Bernal MP, Marshak DW. Serotonergic retinopetal axons in the monkey retina. Curr Eye Res. 2005;30:1089-95.

Gastinger MJ, O'Brien JJ, Larsen NB, Marshak DW. Histamine immunoreactive axons in the macaque retina. Invest Ophthalmol Vis Sci. 1999;40:487-95.

Gattass R, Gross CG. Visual topography of striate projection zone (MT) in posterior superior temporal sulcus of the macaque. J Neurophysiol. 1981;46:621-38.

Gattass R, Gross CG, Sandell JH. Visual topography of V2 in the macaque. J Comp Neurol. 1981;201:519-39.

Gattass R, Rosa MG, Sousa AP, Pinon MC, Fiorani Junior M, Neuenschwander S. Cortical streams of visual information processing in primates. Braz J Med Biol Res. 1990;23:375-93.

Gattass R, Sousa AP, Gross CG. Visuotopic organization and extent of V3 and V4 of the macaque. J Neurosci. 1988;8:1831-45. 
Gattass R, Sousa AP, Rosa MG. Visual topography of V1 in the Cebus monkey. J Comp Neurol. 1987;259:529-48.

Geiman EJ, Knox MC, Alvarez FJ. Postnatal maturation of gephyrin/glycine receptor clusters on developing Renshaw cells. J Comp Neurol. 2000;426:130-42.

Geiman EJ, Zheng W, Fritschy JM, Alvarez FJ. Glycine and GABA(A) receptor subunits on Renshaw cells: relationship with presynaptic neurotransmitters and postsynaptic gephyrin clusters. J Comp Neurol. 2002;444:275-89.

Ghosh KK, Bujan S, Haverkamp S, Feigenspan A, Wassle H. Types of bipolar cells in the mouse retina. J Comp Neurol. 2004;469:70-82.

Greferath U, Grunert U, Fritschy JM, Stephenson A, Mohler H, Wassle H. GABAA receptor subunits have differential distributions in the rat retina: in situ hybridization and immunohistochemistry. J Comp Neurol. 1995;353:553-71.

Greferath U, Grunert U, Muller F, Wassle H. Localization of GABAA receptors in the rabbit retina. Cell Tissue Res. 1994;276:295-307.

Greferath U, Grunert U, Wassle H. Rod bipolar cells in the mammalian retina show protein kinase C-like immunoreactivity. J Comp Neurol. 1990;301:433-42.

Grenningloh G, Rienitz A, Schmitt B, Methfessel C, Zensen M, Beyreuther K et al. The strychnine-binding subunit of the glycine receptor shows homology with nicotinic acetylcholine receptors. Nature. 1987;328:215-20.

Grenningloh G, Schmieden V, Schofield PR, Seeburg PH, Siddique T, Mohandas TK et al. Alpha subunit variants of the human glycine receptor: primary structures, functional expression and chromosomal localization of the corresponding genes. EMBO J. 1990;9:7716.

Grudzinska J, Schemm R, Haeger S, Nicke A, Schmalzing G, Betz H et al. The beta subunit determines the ligand binding properties of synaptic glycine receptors. Neuron. 2005;45:72739.

Grunert U. Distribution of GABAA and glycine receptors in the mammalian retina. Clin Exp Pharmacol Physiol. 1999;26:941-4.

Grunert U, Martin PR, Wassle H. Immunocytochemical analysis of bipolar cells in the macaque monkey retina. J Comp Neurol. 1994;348:607-27.

Grunert U, Wassle $\mathrm{H}$. Immunocytochemical localization of glycine receptors in the mammalian retina. J Comp Neurol. 1993;335:523-37.

Guimaraes PZ, Hokoc JN. Tyrosine hydroxylase expression in the Cebus monkey retina. Vis Neurosci. 1997;14:705-15. 
Gutierrez A, Khan ZU, De Blas AL. Immunocytochemical localization of the alpha 6 subunit of the gamma-aminobutyric acidA receptor in the rat nervous system. J Comp Neurol. 1996;365:504-10.

Hack I, Peichl L, Brandstatter JH. An alternative pathway for rod signals in the rodent retina: rod photoreceptors, cone bipolar cells, and the localization of glutamate receptors. Proc Natl Acad Sci U S A. 1999;96:14130-5.

Hackam AS, Wang TL, Guggino WB, Cutting GR. Sequences in the amino termini of GABA rho and GABA(A) subunits specify their selective interaction in vitro. J Neurochem. 1998;70:40-6.

Hanley JG, Koulen P, Bedford F, Gordon-Weeks PR, Moss SJ. The protein MAP-1B links GABA(C) receptors to the cytoskeleton at retinal synapses. Nature. 1999;397:66-9.

Hartveit E. Functional organization of cone bipolar cells in the rat retina. J Neurophysiol. 1997;77:1716-30.

Harvey RJ, Schmieden V, Von Holst A, Laube B, Rohrer H, Betz H. Glycine receptors containing the alpha4 subunit in the embryonic sympathetic nervous system, spinal cord and male genital ridge. Eur J Neurosci. 2000;12:994-1001.

Hattar S, Kumar M, Park A, Tong P, Tung J, Yau KW et al. Central projections of melanopsin-expressing retinal ganglion cells in the mouse. J Comp Neurol. 2006;497:326-49.

Haverkamp S, Grunert U, Wassle $\mathrm{H}$. The cone pedicle, a complex synapse in the retina. Neuron. 2000;27:85-95.

Haverkamp S, Grunert U, Wassle H. Localization of kainate receptors at the cone pedicles of the primate retina. J Comp Neurol. 2001a;436:471-86.

Haverkamp S, Grunert U, Wassle H. The synaptic architecture of AMPA receptors at the cone pedicle of the primate retina. J Neurosci. 2001b;21:2488-500.

Haverkamp S, Wassle H. Immunocytochemical analysis of the mouse retina. J Comp Neurol. 2000;424:1-23.

Hendrickson AE, Wagoner N, Cowan WM. An autoradiographic and electron microscopic study of retino-hypothalamic connections. Z Zellforsch Mikrosk Anat. 1972;135:1-26.

Hirano AA, Brandstatter JH, Vila A, Brecha NC. Robust syntaxin-4 immunoreactivity in mammalian horizontal cell processes. Vis Neurosci. 2007;24:489-502.

Hirasawa $\mathrm{H}$, Kaneko A. $\mathrm{pH}$ changes in the invaginating synaptic cleft mediate feedback from horizontal cells to cone photoreceptors by modulating Ca2+ channels. J Gen Physiol. 2003;122:657-71.

Hombach S, Janssen-Bienhold U, Sohl G, Schubert T, Bussow H, Ott T et al. Functional expression of connexin57 in horizontal cells of the mouse retina. Eur $\mathrm{J}$ Neurosci. 2004;19:2633-40. 
Pickard GE, Silverman AJ. Direct retinal projections to the hypothalamus, piriform cortex, and accessory optic nuclei in the golden hamster as demonstrated by a sensitive anterograde horseradish peroxidase technique. J Comp Neurol. 1981;196:155-72.

Pinato L, Allemandi W, Abe LK, Frazao R, Cruz-Rizzolo RJ, Cavalcante JS et al. A comparative study of cytoarchitecture and serotonergic afferents in the suprachiasmatic nucleus of primates (Cebus apella and Callithrix jacchus) and rats (Wistar and Long Evans strains). Brain Res. 2007;1149:101-10.

Pinato L, Ferreira ZS, Markus RP, Nogueira MI. Bimodal daily variation in the serotonin content in the raphe nuclei of rats. Biological Rhythm Research. 2004;35:245-257.

Pirker S, Schwarzer C, Wieselthaler A, Sieghart W, Sperk G. GABA(A) receptors: immunocytochemical distribution of 13 subunits in the adult rat brain. Neuroscience. 2000;101:815-50.

Pola J, Wyatt HJ. The role of attention and cognitive processes. Rev Oculomot Res. 1993;5:371-92.

Polenzani L, Woodward RM, Miledi R. Expression of mammalian gamma-aminobutyric acid receptors with distinct pharmacology in Xenopus oocytes. Proc Natl Acad Sci U S A. 1991;88:4318-22.

Polyak SL. The retina. University of Chigaco press 1941.

Pootanakit K, Brunken WJ. 5-HT(1A) and 5-HT(7) receptor expression in the mammalian retina. Brain Res. 2000;875:152-6.

Pootanakit K, Brunken WJ. Identification of 5-HT(3A) and 5-HT(3B) receptor subunits in mammalian retinae: potential pre-synaptic modulators of photoreceptors. Brain Res. 2001;896:77-85.

Pourcho RG, Goebel DJ. A combined Golgi and autoradiographic study of (3H)glycineaccumulating amacrine cells in the cat retina. J Comp Neurol. 1985;233:473-80.

Pourcho RG, Goebel DJ. Visualization of endogenous glycine in cat retina: an immunocytochemical study with Fab fragments. J Neurosci. 1987;7:1189-97.

Pugh EN, Jr., Lamb TD. Amplification and kinetics of the activation steps in phototransduction. Biochim Biophys Acta. 1993;1141:111-49.

Puller C, Haverkamp S, Grunert U. OFF midget bipolar cells in the retina of the marmoset, Callithrix jacchus, express AMPA receptors. J Comp Neurol. 2007;502:442-54.

Qian H, Dowling JE. Novel GABA responses from rod-driven retinal horizontal cells. Nature. 1993;361:162-4.

Qian H, Ripps H. Response kinetics and pharmacological properties of heteromeric receptors formed by coassembly of GABA rho- and gamma 2-subunits. Proc Biol Sci. 1999;266:241925. 
Rao-Mirotznik R, Harkins AB, Buchsbaum G, Sterling P. Mammalian rod terminal: architecture of a binary synapse. Neuron. 1995;14:561-9.

Raviola E, Dacheux RF. Excitatory dyad synapse in rabbit retina. Proc Natl Acad Sci U S A. 1987;84:7324-8.

Raviola E, Gilula NB. Gap junctions between photoreceptor cells in the vertebrate retina. Proc Natl Acad Sci U S A. 1973;70:1677-81.

Reperant J, Araneda S, Miceli D, Medina M, Rio JP. Serotonergic retinopetal projections from the dorsal raphe nucleus in the mouse demonstrated by combined [(3)H] 5-HT retrograde tracing and immunolabeling of endogenous 5-HT. Brain Res. 2000;878:213-7.

Reperant J, Miceli D, Vesselkin NP, Molotchnikoff S. The centrifugal visual system of vertebrates: a century-old search reviewed. Int Rev Cytol. 1989;118:115-71.

Rockhill RL, Daly FJ, MacNeil MA, Brown SP, Masland RH. The diversity of ganglion cells in a mammalian retina. J Neurosci. 2002;22:3831-43.

Rodieck RW. Starburst amacrine cells of the primate retina. J Comp Neurol. 1989;285:18-37.

Rodieck RW, Brening RK. Retinal ganglion cells: properties, types, genera, pathways and trans-species comparisons. Brain Behav Evol. 1983;23:121-64.

Rohrenbeck J, Wassle H, Boycott BB. Horizontal Cells in the Monkey Retina: Immunocytochemical staining with antibodies against calcium binding proteins. Eur $\mathrm{J}$ Neurosci. 1989;1:407-420.

Rohrenbeck J, Wassle H, Heizmann CW. Immunocytochemical labelling of horizontal cells in mammalian retina using antibodies against calcium-binding proteins. Neurosci Lett. 1987;77:255-60.

Rosa MG, Sousa AP, Gattass R. Representation of the visual field in the second visual area in the Cebus monkey. J Comp Neurol. 1988;275:326-45.

Rosas-Arellano A, Ochoa-de la Paz LD, Miledi R, Martinez-Torres A. Brain distribution and molecular cloning of the bovine GABA rho1 receptor. Neurosci Res. 2007;57:347-53.

Rotolo TC, Dacheux RF. Evidence for glycine, GABAA, and GABAB receptors on rabbit OFF-alpha ganglion cells. Vis Neurosci. 2003;20:285-96.

Rusak B, Zucker I. Neural regulation of circadian rhythms. Physiol Rev. 1979;59:449-526.

Saito T, Kujiraoka T, Yonaha T, Chino Y. Reexamination of photoreceptor-bipolar connectivity patterns in carp retina: HRP-EM and Golgi-EM studies. J Comp Neurol. 1985;236:141-60. 
Sassoe-Pognetto M, Kirsch J, Grunert U, Greferath U, Fritschy JM, Mohler H et al. Colocalization of gephyrin and GABAA-receptor subunits in the rat retina. J Comp Neurol. 1995;357:1-14.

Sassoe-Pognetto M, Wassle H, Grunert U. Glycinergic synapses in the rod pathway of the rat retina: cone bipolar cells express the alpha 1 subunit of the glycine receptor. J Neurosci. 1994;14:5131-46.

Schein SJ. Anatomy of macaque fovea and spatial densities of neurons in foveal representation. J Comp Neurol. 1988;269:479-505.

Schmidt M, Humphrey MF, Wassle H. Action and localization of acetylcholine in the cat retina. J Neurophysiol. 1987;58:997-1015.

Schmitt B, Knaus P, Becker CM, Betz H. The Mr 93,000 polypeptide of the postsynaptic glycine receptor complex is a peripheral membrane protein. Biochemistry. 1987;26:805-11.

Schnyder H, Kunzle H. Is there a retinopetal system in the rat? Exp Brain Res. 1984;56:5028.

Schroder S, Hoch W, Becker CM, Grenningloh G, Betz H. Mapping of antigenic epitopes on the alpha 1 subunit of the inhibitory glycine receptor. Biochemistry. 1991;30:42-7.

Seeburg PH, Wisden W, Verdoorn TA, Pritchett DB, Werner P, Herb A et al. The GABAA receptor family: molecular and functional diversity. Cold Spring Harb Symp Quant Biol. 1990;55:29-40.

Shen H, Semba K. A direct retinal projection to the dorsal raphe nucleus in the rat. Brain Res. 1994;635:159-68.

Shimizu T, Cox K, Karten HJ, Britto LR. Cholera toxin mapping of retinal projections in pigeons (Columbia livia), with emphasis on retinohypothalamic connections. Vis Neurosci. 1994;11:441-6.

Sieghart W. Structure and pharmacology of gamma-aminobutyric acidA receptor subtypes. Pharmacol Rev. 1995;47:181-234.

Silveira LC, Lee BB, Yamada ES, Kremers J, Hunt DM. Post-receptoral mechanisms of colour vision in New World primates. Vision Res. 1998;38:3329-37.

Silveira LC, Perry VH, Yamada ES. The retinal ganglion cell distribution and the representation of the visual field in area 17 of the owl monkey, Aotus trivirgatus. Vis Neurosci. 1993;10:887-97.

Silveira LC, Picanco-Diniz CW, Oswaldo-Cruz E. Distribution and size of ganglion cells in the retinae of large Amazon rodents. Vis Neurosci. 1989;2:221-35.

Silveira LC, Picanco-Diniz CW, Sampaio LF, Oswaldo-Cruz E. Retinal ganglion cell distribution in the cebus monkey: a comparison with the cortical magnification factors. Vision Res. 1989;29:1471-83. 
Silveira LC, Yamada ES, Perry VH, Picanco-Diniz CW. M and P retinal ganglion cells of diurnal and nocturnal New-World monkeys. Neuroreport. 1994;5:2077-81.

Simpson JI. The accessory optic system. Annu Rev Neurosci. 1984;7:13-41.

Snodderly DM, Weinhaus RS. Retinal vasculature of the fovea of the squirrel monkey, Saimiri sciureus: three-dimensional architecture, visual screening, and relationships to the neuronal layers. J Comp Neurol. 1990;297:145-63.

Soucy E, Wang Y, Nirenberg S, Nathans J, Meister M. A novel signaling pathway from rod photoreceptors to ganglion cells in mammalian retina. Neuron. 1998;21:481-93.

Stamp JA, Semba K. Extent of colocalization of serotonin and GABA in the neurons of the rat raphe nuclei. Brain Res. 1995;677:39-49.

Stell WK. Correlation of retinal cytoarchitecture and ultrastructure in Golgi preparations. Anat Rec. 1965;153:389-97.

Sterling P. Microcircuitry of the cat retina. Annu Rev Neurosci. 1983;6:149-85.

Sterling P, Demb JB. Retina. In: Synaptic organization of the brain. Oxford University Press 2004, 217- 269.

Sterling P, Freed MA, Smith RG. Architecture of rod and cone circuits to the on-beta ganglion cell. J Neurosci. 1988;8:623-42.

Strettoi E, Dacheux RF, Raviola E. Synaptic connections of rod bipolar cells in the inner plexiform layer of the rabbit retina. J Comp Neurol. 1990;295:449-66.

Tauchi M, Masland RH. The shape and arrangement of the cholinergic neurons in the rabbit retina. Proc R Soc Lond B Biol Sci. 1984;223:101-19.

Taylor WR, Wassle H. Receptive field properties of starburst cholinergic amacrine cells in the rabbit retina. Eur J Neurosci. 1995;7:2308-21.

Tigges J, Tigges M. Distribution of retinofugal and corticofugal axon terminals in the superior colliculus of squirrel monkey. Invest Ophthalmol Vis Sci. 1981;20:149-58.

Todd AJ. GABA and glycine in synaptic glomeruli of the rat spinal dorsal horn. Eur $\mathrm{J}$ Neurosci. 1996;8:2492-8.

Todd AJ, Watt C, Spike RC, Sieghart W. Colocalization of GABA, glycine, and their receptors at synapses in the rat spinal cord. J Neurosci. 1996;16:974-82.

Tsukamoto Y, Masarachia P, Schein SJ, Sterling P. Gap junctions between the pedicles of macaque foveal cones. Vision Res. 1992;32:1809-15.

Tsukamoto Y, Morigiwa K, Ueda M, Sterling P. Microcircuits for night vision in mouse retina. J Neurosci. 2001;21:8616-23. 
Turek FW. Circadian rhythms. Recent Prog Horm Res. 1994;49:43-90.

Uchiyama H, Aoki K, Yonezawa S, Arimura F, Ohno H. Retinal target cells of the centrifugal projection from the isthmo-optic nucleus. J Comp Neurol. 2004;476:146-53.

Ueda S, Kawata M, Sano Y. Identification of neuropeptide $\mathrm{Y}$ immunoreactivity in the suprachiasmatic nucleus and the lateral geniculate nucleus of some mammals. Neurosci Lett. 1986;68:7-10.

Vaney DI. The morphology and topographic distribution of AII amacrine cells in the cat retina. Proc R Soc Lond B Biol Sci. 1985;224:475-88.

Vaney DI. Territorial organization of direction-selective ganglion cells in rabbit retina. J Neurosci. 1994;14:6301-16.

Vaney DI, Gynther IC, Young HM. Rod-signal interneurons in the rabbit retina: 2. AII amacrine cells. J Comp Neurol. 1991;310:154-69.

Vaney DI, Nelson JC, Pow DV. Neurotransmitter coupling through gap junctions in the retina. J Neurosci. 1998;18:10594-602.

Vaney DI, Whitington GE, Young HM. The morphology and topographic distribution of substance-P-like immunoreactive amacrine cells in the cat retina. Proc R Soc Lond B Biol Sci. 1989;237:471-88.

Vardi N, Duvoisin R, Wu G, Sterling P. Localization of mGluR6 to dendrites of ON bipolar cells in primate retina. J Comp Neurol. 2000;423:402-12.

Vardi N, Sterling P. Subcellular localization of GABAA receptor on bipolar cells in macaque and human retina. Vision Res. 1994;34:1235-46.

Vertes RP. A PHA-L analysis of ascending projections of the dorsal raphe nucleus in the rat. J Comp Neurol. 1991;313:643-68.

Villar MJ, Vitale ML, Hokfelt T, Verhofstad AA. Dorsal raphe serotoninergic branching neurons projecting both to the lateral geniculate body and superior colliculus: a combined retrograde tracing-immunohistochemical study in the rat. J Comp Neurol. 1988;277:126-40.

Villar MJ, Vitale ML, Parisi MN. Dorsal raphe serotonergic projection to the retina. A combined peroxidase tracing-neurochemical/high-performance liquid chromatography study in the rat. Neuroscience. 1987;22:681-6.

Vitanova L, Kupenova P, Haverkamp S, Popova E, Mitova L, Wassle H. Immunocytochemical and electrophysiological characterization of GABA receptors in the frog and turtle retina. Vision Res. 2001;41:691-704.

Wassle H. Parallel processing in the mammalian retina. Nat Rev Neurosci. 2004;5:747-57. 
Wassle H, Boycott BB. Functional architecture of the mammalian retina. Physiol Rev. 1991;71:447-80.

Wassle H, Boycott BB, Rohrenbeck J. Horizontal Cells in the Monkey Retina: Cone connections and dendritic network. Eur J Neurosci. 1989;1:421-435.

Wassle $\mathrm{H}$, Grunert U, Chun $\mathrm{MH}$, Boycott BB. The rod pathway of the macaque monkey retina: identification of AII-amacrine cells with antibodies against calretinin. J Comp Neurol. 1995;361:537-51.

Wassle H, Grunert U, Martin PR, Boycott BB. Immunocytochemical characterization and spatial distribution of midget bipolar cells in the macaque monkey retina. Vision Res. 1994;34:561-79.

Wassle H, Grunert U, Rohrenbeck J. Immunocytochemical staining of AII-amacrine cells in the rat retina with antibodies against parvalbumin. J Comp Neurol. 1993;332:407-20.

Wassle H, Koulen P, Brandstatter JH, Fletcher EL, Becker CM. Glycine and GABA receptors in the mammalian retina. Vision Res. 1998;38:1411-30.

Wassle H, Yamashita M, Greferath U, Grunert U, Muller F. The rod bipolar cell of the mammalian retina. Vis Neurosci. 1991;7:99-112.

Watanabe M, Rodieck RW. Parasol and midget ganglion cells of the primate retina. J Comp Neurol. 1989;289:434-54.

Waterhouse BD, Border B, Wahl L, Mihailoff GA. Topographic organization of rat locus coeruleus and dorsal raphe nuclei: distribution of cells projecting to visual system structures. $\mathrm{J}$ Comp Neurol. 1993;336:345-61.

Weber JT. Pretectal complex and accessory optic system of primates. Brain Behav Evol. 1985;26:117-40.

Weber JT, Hutchins B. The demonstration of a retinal projection to the medial pretectal nucleus in the domestic cat and the squirrel monkey: an autoradiographic analysis. Brain Res. 1982;232:181-6.

Wegelius K, Pasternack M, Hiltunen JO, Rivera C, Kaila K, Saarma M et al. Distribution of GABA receptor rho subunit transcripts in the rat brain. Eur J Neurosci. 1998;10:350-7.

Weiler R, Pottek M, He S, Vaney DI. Modulation of coupling between retinal horizontal cells by retinoic acid and endogenous dopamine. Brain Res Brain Res Rev. 2000;32:121-9.

Wiesel TN, Hubel DH. Spatial and chromatic interactions in the lateral geniculate body of the rhesus monkey. J Neurophysiol. 1966;29:1115-56.

Wolter JR. Electron microscopic demonstration of centrifugal nerve fibers in the human optic nerve. Albrecht Von Graefes Arch Klin Exp Ophthalmol. 1979;210:31-41. 
Wu SM, Gao F, Maple BR. Functional architecture of synapses in the inner retina: segregation of visual signals by stratification of bipolar cell axon terminals. J Neurosci. 2000;20:4462-70.

Yamada ES. Organização morfofuncional do sistema visual de primatas Platirrinos: análise quantitativa da morfologia, densidade e cobertura dendrítica das células ganglionares retinianas $\mathrm{M}$ e $\mathrm{P}$ de Cebus e Aotus. [grau (Tese de doutorado)]. Belém (Brasil): da Universidade Federal do Pará e Museu Paraense Emílio Goeldi; 1995.

Yamada ES, Silveira LC, Gomes FL, Lee BB. The retinal ganglion cell classes of New World primates. Rev Bras Biol. 1996;56 Su 1 Pt 2:381-96.

Yamada ES, Silveira LC, Perry VH. Morphology, dendritic field size, somal size, density, and coverage of $\mathrm{M}$ and $\mathrm{P}$ retinal ganglion cells of dichromatic Cebus monkeys. Vis Neurosci. 1996;13:1011-29.

Yamada ES, Silveira LC, Perry VH, Franco EC. M and P retinal ganglion cells of the owl monkey: morphology, size and photoreceptor convergence. Vision Res. 2001;41:119-31.

Yeh HH, Grigorenko EV, Veruki ML. Correlation between a bicuculline-resistant response to GABA and GABAA receptor rho 1 subunit expression in single rat retinal bipolar cells. Vis Neurosci. 1996;13:283-92.

Yellon SM, Thorn KJ, Buchanan KL, Kirby MA. Retinal input to the suprachiasmatic nucleus before and after puberty in Djungarian hamsters. Brain Res Bull. 1993;32:29-33.

Youngstrom TG, Weiss ML, Nunez AA. Retinofugal projections to the hypothalamus, anterior thalamus and basal forebrain in hamsters. Brain Res Bull. 1991;26:403-11.

Zhang D, Pan ZH, Awobuluyi M, Lipton SA. Structure and function of GABA(C) receptors: a comparison of native versus recombinant receptors. Trends Pharmacol Sci. 2001;22:121-32.

Zhang D, Pan ZH, Zhang X, Brideau AD, Lipton SA. Cloning of a gamma-aminobutyric acid type $C$ receptor subunit in rat retina with a methionine residue critical for picrotoxinin channel block. Proc Natl Acad Sci U S A. 1995;92:11756-60.

Zhou ZJ, Fain GL. Neurotransmitter receptors of starburst amacrine cells in rabbit retinal slices. J Neurosci. 1995;15:5334-45.

\section{ANEXO A.}

Evidence of reciprocal connections between the dorsal raphe nucleus and the retina in the monkey Cebus apella. 